\title{
Associations of Disease-Modifying Therapies With COVID-19 Severity in Multiple Sclerosis
}

Steve Simpson-Yap, PhD, MPH, * Edward De Brouwer, MSc, * Tomas Kalincik, MD, PhD, PGCertBiostat, Nick Rijke, MA, Jan A. Hillert, MD, PhD, Clare Walton, PhD, Gilles Edan, MD, Yves Moreau, PhD, Tim Spelman, PhD, Lotte Geys, PhD, Tina Parciak, MSc, Clement Gautrais, PhD, Nikola Lazovski, PDEng, Ashkan Pirmani, MSc, Amin Ardeshirdavanai, PhD, Lars Forsberg, MSc, Anna Glaser, PhD, Robert McBurney, PhD, Hollie Schmidt, MS, Arnfin B. Bergmann, MD, PhD, Stefan Braune, PhD, Alexander Stahmann, MSc, Rodden Middleton, MBA, Amber Salter, PhD, Robert J. Fox, MD, Anneke van der Walt, PhD, Helmut Butzkueven, PhD, Raed Alroughani, PhD, Serkan Ozakbas, PhD, Juan I. Rojas, MSc, Ingrid van der Mei, PhD, Nupur Nag, PhD, Rumen Ivanov, MSc, Guilherme Sciascia do Olival, PhD, Alice Estavo Dias, PhD, Melinda Magyari, PhD, Doralina Brum, PhD, Maria Fernanda Mendes, PhD, Ricardo N. Alonso, MD, MSc, Richard S. Nicholas, PhD, Johana Bauer, PhD, Aníbal Sebastián Chertcoff, MD, Anna Zabalza, MD, Georgina Arrambide, MD, PhD, Alexander Fidao, MPH, Giancarlo Comi, MD, $†$ and Liesbet Peeters, PhD†

Neurology ${ }^{\circledR}$ 2021;97:e1870-e1885. doi:10.1212/WNL.0000000000012753

\section{Abstract}

\section{Background and Objectives}

People with multiple sclerosis (MS) are a vulnerable group for severe coronavirus disease 2019 (COVID-19), particularly those taking immunosuppressive disease-modifying therapies (DMTs). We examined the characteristics of COVID-19 severity in an international sample of people with MS.

\section{Methods}

Data from 12 data sources in 28 countries were aggregated (sources could include patients from 1-12 countries). Demographic (age, sex), clinical (MS phenotype, disability), and DMT (untreated, alemtuzumab, cladribine, dimethyl fumarate, glatiramer acetate, interferon, natalizumab, ocrelizumab, rituximab, siponimod, other DMTs) covariates were queried, along with COVID-19 severity outcomes, hospitalization, intensive care unit (ICU) admission, need for artificial ventilation, and death. Characteristics of outcomes were assessed in patients with suspected/ confirmed COVID-19 using multilevel mixed-effects logistic regression adjusted for age, sex, MS phenotype, and Expanded Disability Status Scale (EDSS) score.

\author{
Correspondence \\ Dr. Liesbet Peeters \\ liesbet.peeters@uhasselt.be
}

\section{RELATED ARTICLE}

Editorial

B-Cell Depletion and COVID-19 Severity in Multiple Sclerosis: Remaining Challenges

Page 885

MORE ONLINE

\section{(๑) Podcast}

Npub.org/Podcast9719

\section{COVID-19 Resources}

For the latest articles, invited commentaries, and blogs from physicians around the world

NPub.org/COVID19

\footnotetext{
*These authors contributed equally to this work as first authors.
}

tThese authors contributed equally to this work as senior authors.

From the CORe (S.S.-Y., T.K.), Department of Medicine, and Neuroepidemiology Unit (S.S.-Y., N.N., A.F.), Melbourne School of Population \& Global Health, University of Melbourne, Parkville, Australia; Menzies Institute for Medical Research (S.S.-Y.), University of Tasmania, Hobart, Australia; ESAT-STADIUS (E.D.B., Y.M., A.P.), KU Leuven, Belgium; Department of Neurology (T.K.), Melbourne MS Centre, Royal Melbourne Hospital, Parkville, Australia; MS International Federation (N.R., C.W.), London, UK; Department of Clinical Neuroscience (J.A.H., T.S., L.F., A.G.), Swedish MS Registry, Stockholm, Sweden; Department of Neurology (G.E.), CHU Pontchaillou, Rennes, France; Karolinska Institutet (T.S.), Solna, Sweden; Biomedical Research Institute-Data Science Institute (L.G., A.P., L.P.), Hasselt University, Belgium; Department of Medical Informatics (T.P.), University Medical Center Göttingen, Germany; Department of Computer Science and Al (C.G.), KU Leuven, Belgium; QMENTA (N.L.), Barcelona, Spain; Medpace Reference Laboratories (A.A.), Molecular Unit, Leuven, Belgium; iConquerMS People-Powered Research Network (R. McBurney, H.S.), Accelerated Cure Project for MS, Waltham, MA; NeuroTransData Study Group (A.B.B., S.B.), NeuroTransData, Neuburg, Germany; German MS-Register by the National MS Society (A. Stahmann), MS Forschungs- und Projektentwicklungs-gGmbH, Hannover, Germany; UK MS Register (R. Middleton, R.S.N.), Swansea University, UK; COViMS (A. Salter, R.J.F.), US; Division of Biostatistics (A. Salter), Washington University in St. Louis, St Louis, MO; Mellen Center for Multiple Sclerosis (R.J.F.), Cleveland Clinic, Cleveland, OH; Department of Neuroscience (A.v.d.W., H.B.), Central Clinical School, Monash University, Melbourne, Australia; Al-Amiri Hospital (R.A.), Kuwait City, Kuwait; Dokuz Eylul University (S.O.), Izmir, Turkey; Neurology Department (J.I.R.), Hospital Universitario de CEMIC; RELACOEM (.I.R., R.N.A.), Buenos Aires, Argentina; Australian MS Longitudinal Study (I.v.d.M.), Menzies Institute for Medical Research, University of Tasmania, Hobart, Australia; Bulgarian SmartMS COVID-19 Dataset (R.I.), Sofia, Bulgaria; ABEM-Brazilian MS Patients Association (G.S.d.O., A.E.D.), São Paulo, Brazil; Danish Multiple Sclerosis Registry (M.M.), Department of Neurology, University Hospital Rigshospitalet, Glostrup, Denmark; Universidade Estadual Paulista (D.B.), Unesp, Faculdade de Medicina, Botucatu, Brazil; REDONE.br-Brazilian Registry of Multiple Sclerosis and Neuromyelitis Optica Spectrum Disorders (D.B., M.F.M.); Irmandade da Santa Casa de Misericórdia de São Paulo (M.F.M.), Brazil; Multiple Sclerosis University Center (R.N.A.), Ramos Mejia Hospital-EMA, Buenos Aires, Argentina; Imperial College London (R.S.N.); Swansea University (R.S.N.), Swansea, UK; Mental Health Area (I.B.); MS and Demyelinating Diseases (A.S.C.)., Hospital Británico de Buenos Aires, EMA, Argentina; Servei de Neurologia-Neuroimmunologia (A.Z., G.A.), Centre d’Esclerosi Múltiple de Catalunya, (Cemcat); Vall d'Hebron Institut de Recerca (A.Z., G.A.), Vall d'Hebron Hospital Universitari; Universitat Autònoma de Barcelona (A.Z., G.A.), Spain; and Institute of Experimental Neurology (G.C.), Ospedale San Raffaele, Milan, Italy.

Go to Neurology.org/N for full disclosures. Funding information and disclosures deemed relevant by the authors, if any, are provided at the end of the article. 


\section{Glossary}

aOR = adjusted OR; BMI = body mass index; CI = confidence interval; COVID-19 = coronavirus disease 2019; DMT = disease-modifying therapy; EDSS = Expanded Disability Status Scale; ICU = intensive care unit; MS = multiple sclerosis; MSDA = MS Data Alliance; OR = odds ratio; RRMS = relapsing-remitting MS; SARS-CoV-2 = severe acute respiratory syndrome coronavirus 2 .

\section{Results}

Six hundred fifty-seven (28.1\%) with suspected and 1,683 (61.9\%) with confirmed COVID-19 were analyzed. Among suspected plus confirmed and confirmed-only COVID-19, 20.9\% and $26.9 \%$ were hospitalized, $5.4 \%$ and $7.2 \%$ were admitted to ICU, $4.1 \%$ and 5.4\% required artificial ventilation, and 3.2\% and 3.9\% died. Older age, progressive MS phenotype, and higher disability were associated with worse COVID-19 outcomes. Compared to dimethyl fumarate, ocrelizumab and rituximab were associated with hospitalization (adjusted odds ratio [aOR] 1.56, 95\% confidence interval [CI] 1.01-2.41; aOR 2.43, 95\% CI 1.48-4.02) and ICU admission (aOR 2.30, 95\% CI 0.98-5.39; aOR 3.93, 95\% CI 1.56-9.89), although only rituximab was associated with higher risk of artificial ventilation (aOR 4.00, 95\% CI 1.54-10.39). Compared to pooled other DMTs, ocrelizumab and rituximab were associated with hospitalization (aOR 1.75, 95\% CI 1.29-2.38; aOR 2.76, 95\% CI 1.87-4.07) and ICU admission (aOR 2.55, 95\% CI 1.49-4.36; aOR 4.32, 95\% CI 2.27-8.23), but only rituximab was associated with artificial ventilation (aOR 6.15, 95\% CI 3.09-12.27). Compared to natalizumab, ocrelizumab and rituximab were associated with hospitalization (aOR 1.86, 95\% CI 1.13-3.07; aOR 2.88, 95\% CI 1.68-4.92) and ICU admission (aOR 2.13, 95\% CI 0.85-5.35; aOR 3.23, 95\% CI 1.17-8.91), but only rituximab was associated with ventilation (aOR 5.52, 95\% CI 1.71-17.84). Associations persisted on restriction to confirmed COVID-19 cases. No associations were observed between DMTs and death. Stratification by age, MS phenotype, and EDSS score found no indications that DMT associations with COVID-19 severity reflected differential DMT allocation by underlying COVID-19 severity.

\section{Discussion}

Using the largest cohort of people with MS and COVID-19 available, we demonstrated consistent associations of rituximab with increased risk of hospitalization, ICU admission, and need for artificial ventilation and of ocrelizumab with hospitalization and ICU admission. Despite the cross-sectional design of the study, the internal and external consistency of these results with prior studies suggests that rituximab/ocrelizumab use may be a risk factor for more severe COVID-19.

Disease-modifying therapies (DMTs) that act by immunomodulatory/immunosuppressive mechanisms are a mainstay of treatment of multiple sclerosis (MS) but can increase infection susceptibility. ${ }^{1}$ Cross-sectional ${ }^{2}$ and cohort $^{3-5}$ studies suggest that comorbid conditions, age, sex, progressive MS phenotype, and higher disability increase risk for developing severe coronavirus disease 2019 (COVID-19). ${ }^{3,5}$ Some studies have also identified associations of certain DMT classes with COVID-19 severity. ${ }^{3}$ Using the French Covisep registry, the authors assessed 347 patients with MS with suspected/ confirmed COVID-19, finding those treated with DMTs with a greater risk of systemic infection (alemtuzumab/cladribine/ fingolimod/ocrelizumab/rituximab) had $>4$ times higher proportions with severe COVID-19 than DMTs with no infection risk (interferon beta/glatiramer acetate). ${ }^{3}$ Using the MuSC-19 retrospective cohort study, authors assessed COVID-19 severity among 844 patients with MS with suspected/confirmed COVID-19, finding that those treated with anti-CD20 DMTs (ocrelizumab/rituximab) had 2.4 times higher risk of severe COVID-19 compared to those treated with dimethyl fumarate. ${ }^{5}$ The COVID in MS (COViMS) Registry assessed characteristics of COVID-19 severity among 1,626 people with MS with suspected/confirmed COVID-19, finding that, compared to the untreated patients, ocrelizumab-treated (odds ratio [OR] 1.63) and rituximab-treated (OR 4.56) patients had higher frequencies of hospitalization, although no associations with intensive care unit (ICU) admission/ventilation or death were seen. ${ }^{2}$

Large and geographically inclusive cohorts are required to assess the risk of severe COVID-19 for specific DMTs. Accordingly, we established a global data-sharing initiative ${ }^{6}$ to investigate characteristics of COVID-19 severity in people with MS. We hypothesized that older age, progressive MS phenotype, and higher disability were associated with more severe COVID-19, while immunosuppressive DMTs (alemtuzumab/cladribine/ fingolimod/ocrelizumab/rituximab) would be deleterious, but those with less infection risk (interferons/glatiramer acetate) would be associated with a less severe COVID-19.

\section{Methods}

\section{Standard Protocol Approvals, Registrations, and Patient Consents}

This study received approval from an ethics standards committee on human experimentation (institutional or regional) for any experiments using human participants (ethics committee of Hasselt University, CME2020/025). Other ethics information from data custodians includes the following. 
MSBase data are provided with the consent of individual participants and principal investigators at each MSBase participating center. The German MS-Register was first approved by ethics committee of Julius-Maximilians-University of Würzburg (vote $142 / 12$ ). After a switch was made to the web-based documentation system, further positive votes, for example, by the ethics committee of the Thuringia State chamber of physicians, followed by several ethics committees of different universities, were given, and all patients signed an informed consent.

Research participant protection was sought from the Washington University in St. Louis Institutional Review Board for housing COViMS Registry data, who determined it to be not human participants research and therefore exempt from active Institutional Review Board oversight at Washington University in St. Louis and did not require patient consent.

The patient data sent to analyses resulting in the Associations of DMT Therapies With COVID-19 Severity in Multiple Sclerosis study originated from a study approved by the ethics committee of the Faculdade de Medicina de Botucatu, Universidade Estadual Paulista under the internal review board number CAAE 31021220.2.0000.5411. All participants signed a written informed consent form before enrollment.

The Centre d'Esclerosi Múltiple de Catalunya cohort study was approved by the ethics committee of the Vall d'Hebron University Hospital (XMG-INT-2014-01), and all patients signed an informed consent.

Data from a core questionnaire on COVID-19 and relevant demographic/clinical information were reported by treating clinicians. The methods underlying the MS Data Alliance (MSDA) COVID-19 collaboration and measures thereof have been described previously. ${ }^{6}$ Briefly, treating clinicians entered information on a range of demographic, lifestyle, and MSspecific and COVID-19-specific clinical characteristics. Here, only age, sex, MS phenotype, disability, DMTs, smoking, body mass index (BMI), comorbid conditions, COVID-19 status, hospitalization, ICU admission, artificial ventilation, and death are described. Study participation was restricted to patients with MS who were $\geq 18$ years of age; however, this article is limited to those with suspected/confirmed COVID-19.

Data were entered in 3 fashions: (1) direct entry to central platform; (2) patient-level data sharing via participating registries/cohorts, whereby MS registries and cohorts are regularly invited to share and upload their COVID-19 core dataset into the central data platform; and (3) aggregated data sharing via participating registries/cohorts, whereby some registries do not share data from individual patients but share aggregated results from specific queries.

Multidimensional contingency tables from 12 different data sources were merged, and then a combined anonymized dataset was reconstructed. Not all patients at each contributing data source necessarily participated in this study.
Indeed, given the high proportion of patients with suspected and confirmed COVID-19, it is likely that a minority of patients at each center participated.

Data were entered for a given participant once, but information for that participant could be reentered, and these reentered data replaced the original record. This made for serial iterations of the analysis dataset, which were analyzed over time as the dataset expanded, thus allowing for assessment of temporal consistency of observed associations between the versions of the dataset. In this fashion, if associations were erratic in their appearance between iterations, this might suggest them to be statistical artifact, whereas consistency would indicate their veracity.

To improve the quality of the data continuously over time, we set up a data quality assessment and enhancement pipeline. This pipeline consists of 2 major parts: unambiguously defining new variables that are used in downstream analysis (e.g., defining COVID-19 suspected and confirmed cases, categorizing continuous variables to allow aggregation of the counts) and predefining pass/fail criteria for variables (e.g., negative ages, unrealistically high numbers for height). Variables that fail were flagged, and registry custodians were contacted to repair failed variables in the next upload. Simultaneously, failed variables were cleaned and preprocessed so that records could be incorporated into the downstream analysis.

\section{Variables}

Definitions for all terms were provided to data partners and were available on the MSDA platform. Clinicians made all judgments regardless of how data were entered. This data dictionary is available by contacting the corresponding author.

COVID-19 status was defined as confirmed, based on a positive diagnostic test, or suspected, based on clinician judgment.

Hospitalization was queried as admission to hospital because of COVID-19 (suspicious) infection. ICU admission was queried as stay in ICU because of COVID-19 (suspicious) infection. Requiring artificial ventilation was queried as ventilation needed during hospital stay. Death due to COVID-19 was queried as "did the patient die because of the (suspected) COVID-19 infection?"

Patient age was categorized into 3 age groups: 18 to 49,50 to 69 , and $\geq 70$ years. MS phenotype was grouped into relapsingremitting MS (RRMS) and progressive MS (secondary and primary progressive MS).

Disability was assessed by the Expanded Disability Status Scale (EDSS) ${ }^{7}$ or Neurostatus. ${ }^{8}$ Disability was dichotomized into scores of 0 to 6.0 and $>6.0$. Comorbid conditions were queried, including cardiovascular disease, hypertension, diabetes, chronic liver disease, kidney disease, other neurologic/ neuromuscular disorder, lung disease, or malignant neoplasia. BMI was categorized as nonobese $\left(B M I \leq 30 \mathrm{~kg} / \mathrm{m}^{2}\right)$ and obese $\left(\mathrm{BMI}>30 \mathrm{~kg} / \mathrm{m}^{2}\right)$. Current smoker status was queried as 
yes or no. Current DMT use was queried, including alemtuzumab, cladribine, dimethylfumarate, fingolimod, glatiramer acetate, interferons, natalizumab, ocrelizumab, rituximab, siponimod, teriflunomide, or other DMT, which was queried as on another drug not listed. Due to patient numbers $<20$ among the suspected/confirmed COVID-19 cases, siponimod ( $\mathrm{n}=$ 12) was aggregated with other DMT. Note that aggregation of siponimod with fingolimod did not materially change results (data not shown).

\section{Statistical Analysis}

Associations with hospitalization, ICU admission, ventilation, and death were assessed with multilevel mixed-effects logistic regression, random effects grouped by data source, as univariable and adjusted for age, sex, MS phenotype, and disability. Multilevel mixed-effects logistic regression is an appropriate methodology wherein multiple data sources with heterogeneity in cohort characteristics or methods are included. This method applies fixed and random effects to the model, accounting for intraclass correlation for observations within data sources, providing aggregate statistics for the measures of association of the independent model covariates. While all data sources used the same data entry framework and core questionnaire, there are differences in the modes of clinical practice, for MS- and infection-related care, as well as clinical and demographic characteristics, which need be accounted for and for which this statistical method is suited.

Subgroup analyses were also undertaken whereby data on comorbid condition, BMI, and smoking were available, allowing additional adjustment for these covariates. All analyses were complete case.

For DMTs, individual DMTs were first compared with dimethyl fumarate. Despite leading to lymphopenia in some patients, dimethyl fumarate has not been associated with increased infection risk, ${ }^{9}$ and its biological mechanism of action is unlikely to interfere with anti-severe acute respiratory syndrome coronavirus 2 (SARS-CoV-2) immunologic respons $\mathrm{e}^{10}$ while being common in the sample. Of note, interferons and glatiramer acetate were considered as potential comparators, but the lack of failures across all 4 outcomes for these DMTs precluded their being the reference group. Next, ocrelizumab, rituximab, and untreated were compared against all other pooled DMTs. Finally, ocrelizumab and rituximab were evaluated vs natalizumab to assess ascertainment bias because natalizumab-treated patients present for infusions every 28 to 42 days compared to biannual infusions for anti-CD20 DMTs.

Adjustment for multiple comparisons was undertaken with the family-wise Holm step-down method, such that within each hypothesis and within models 1 and 2, statistical tests were ranked by lowest $p$ value and significance threshold evaluated relative to the number of statistical tests within that family. Associations reaching significance after this adjustment are annotated as such in tables.
Table 1 Cohort Characteristics

\begin{tabular}{|c|c|c|}
\hline & $\begin{array}{l}\text { Suspected and } \\
\text { confirmed } \\
(n=2,340), n(\%)\end{array}$ & $\begin{array}{l}\text { Confirmed } \\
(n=1,683), n(\%)\end{array}$ \\
\hline Confirmed COVID-19 status & $1,683(71.9)$ & $1,683(100.0)$ \\
\hline Hospitalization & 489 (20.9) & $453(26.9)$ \\
\hline ICU admission & $127(5.4)$ & $122(7.2)$ \\
\hline Ventilation & $97(4.1)$ & $91(5.4)$ \\
\hline Death & $73(3.2)$ & $65(3.9)$ \\
\hline Female & $1702(72.7)$ & $1,213(72.1)$ \\
\hline \multicolumn{3}{|l|}{ Age, y } \\
\hline $18-<50$ & $1,505(64.3)$ & $1,032(61.3)$ \\
\hline $50-<70$ & $740(31.6)$ & $571(33.9)$ \\
\hline$\geq 70$ & $83(3.5)$ & $72(4.3)$ \\
\hline RRMS phenotype & $2,119(80.4)$ & $1,854(80.5)$ \\
\hline EDSS score 0-6 & $1,837(78.5)$ & $1,275(75.8)$ \\
\hline Has comorbid conditions & $920(40.7)$ & $707(43.2)$ \\
\hline Obese BMI & $437(19.3)$ & $376(23.0)$ \\
\hline Current smoker & $166(7.3)$ & $115(7.0)$ \\
\hline \multicolumn{3}{|l|}{ DMT } \\
\hline Untreated & $284(12.1)$ & $231(13.7)$ \\
\hline Alemtuzumab & $31(1.3)$ & $26(1.5)$ \\
\hline Cladribine & $29(1.2)$ & $17(1.0)$ \\
\hline Dimethyl fumarate & $275(11.8)$ & $199(11.8)$ \\
\hline Fingolimod & $200(8.5)$ & $143(8.5)$ \\
\hline Glatiramer acetate & $87(3.7)$ & $70(4.2)$ \\
\hline Interferon & $124(5.3)$ & $85(5.1)$ \\
\hline Natalizumab & $221(9.4)$ & $164(9.7)$ \\
\hline Ocrelizumab & $471(20.1)$ & $365(21.7)$ \\
\hline Rituximab & $258(11.0)$ & $142(8.4)$ \\
\hline Teriflunomide & $97(4.1)$ & $75(4.5)$ \\
\hline Other DMT & $70(3.0)$ & $47(2.8)$ \\
\hline
\end{tabular}

Abbreviations: $\mathrm{BMI}=$ body mass index; COVID-19 = coronavirus disease 2019; DMT = disease-modifying therapy, EDSS = Expanded Disability Status Scale; ICU = intensive care unit; RRMS = relapsing-remitting multiple sclerosis.

Data analyses were carried out with STATA/SE 16.0 (StataCorp, College Station, TX).

\section{Data Availability}

Persons interested in acquiring the anonymized data underlying this analysis can inquire with a senior author (L.P.) to make requests. In addition, supplementary tables not included in the main body text can be found in the preprint version of the article, accessible at doi.org/10.1101/2021.02.08.21251316. 
Figure 1 Characteristics of Patients Treated With Ocrelizumab, Rituximab, or Other DMTs or Untreated, by Sex, Age, MS Phenotype, and Disability

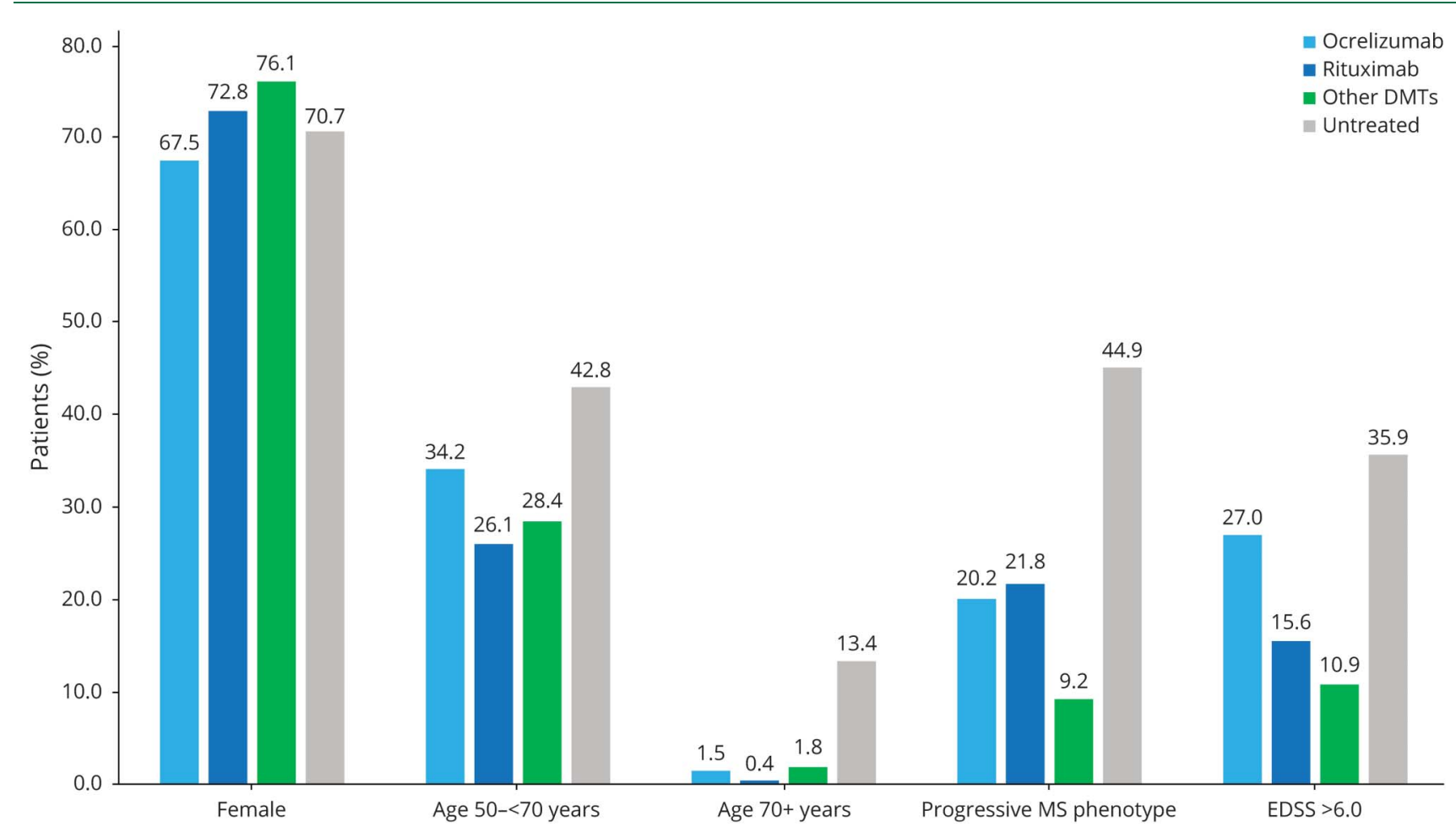

DMT = disease-modifying therapy; EDSS = Expanded Disability Status Scale; MS = multiple sclerosis.

\section{Results}

The cohort comprised 2,340 patients, of whom 657 (28.1\%) had suspected COVID-19 and 1,683 (71.9\%) had confirmed COVID-19. Among suspected/confirmed COVID-19 cases, which made up the primary analysis dataset, $20.9 \%$ were hospitalized, 5.4\% were admitted to ICU, $4.1 \%$ required artificial ventilation, and $3.2 \%$ died. Proportions were slightly higher among confirmed COVID-19 cases (Table 1).

\section{Cohort Characteristics}

Data sources were located in (1) Sweden ( $\mathrm{n}=290)$; (2) Australia, Belgium, Brazil, Kuwait, Romania, Saudi Arabia, and Turkey ( $\mathrm{n}=97)$; (3) Argentina, Chile, Colombia, Ecuador, Honduras, and Mexico ( $\mathrm{n}=159)$; (4) Bulgaria ( $\mathrm{n}=3)$; (5) Germany and Italy $(\mathrm{n}=45)$; (6) Denmark $(\mathrm{n}=56)$; (7) Brazil ( $\mathrm{n}=96)$; (8) Australia, Bahamas, Belgium, Czech Republic, Finland, France, the Netherlands, New Zealand, Serbia, Spain, the United Kingdom, and the United States ( $\mathrm{n}=114$ ); (9) Germany $(\mathrm{n}=41)$; $(10)$ the United States and Canada $(\mathrm{n}=$ 1,161); (11) the United Kingdom ( $\mathrm{n}=131)$; and (12) Spain $(\mathrm{n}=147)$. Sources 2 and 10 had higher proportions with confirmed COVID-19, and sources 4 and 5 had higher proportions with nonsuspected COVID-19. Among suspected/ confirmed COVID-19 cases, hospitalization was higher in source 11 and lower in sources 2, 4, 5, and 7; ICU admission was higher in sources 3,9, and 10 and lower in sources 2, 4, 7, 9,11 , and 12; ventilation was higher in sources 3 and 8 and lower in sources 2, 4 through 7, 9, and 11; and death was higher in source 11 and lower in sources 2 and 4 through 9. Results were comparable on restriction to confirmed-only COVID-19 (data not shown).

Compared to dimethyl fumarate (76.1\%), lower proportions of female patients were untreated $(70.7 \%)$ or treated with interferon $(69.4 \%)$ or ocrelizumab (67.5\%, eTable 1, links.lww. com/WNL/B520). Larger proportions of those 50 to 69 and $\geq 70$ years of age were untreated $(42.8 \%, 13.4 \%)$ or treated with ocrelizumab (34.2\%, $1.5 \%)$, teriflunomide (49.5\%, $3.1 \%)$, or other DMTs $(37.7 \%, 5.8 \%)$ than with dimethyl fumarate (29.9\%, 0.8\%). Greater proportions of patients with progressive MS were untreated (44.9\%) or treated with ocrelizumab (20.2\%), rituximab $(21.8 \%)$, or other DMTs (31.9\%) than with dimethyl fumarate $(8.0 \%)$. Of patients with greater disability (EDSS score $>6$ ), higher proportions were either untreated $(35.9 \%)$ or treated with ocrelizumab $(27.0 \%)$ or other DMTs (34.8\%) than with dimethyl fumarate (7.6\%). Similar results were seen among confirmed-only COVID-19 (data not shown).

In evaluations of ocrelizumab and rituximab compared to pooled other DMTs and the untreated (Figure 1), anti-CD20 DMTs were comparable by sex and MS phenotype, but a greater proportion of ocrelizumab-treated patients were 50 to 69 years of age and had an EDSS score $\leq 6$. Greater proportions of anti-CD20-treated patients were of the progressive MS phenotype or had an EDSS score $>6$ than those treated with the 
Table 2 Characteristics of COVID-19 Severity Outcomes, DMTs vs Dimethyl Fumarate, Suspected Plus Confirmed COVID-19

\begin{tabular}{|c|c|c|c|c|c|c|}
\hline & \multicolumn{3}{|c|}{ Hospitalization } & \multicolumn{3}{|c|}{ ICU admission } \\
\hline & n (\%) & OR $(95 \% \mathrm{Cl})$ & $\operatorname{aOR}(95 \% \mathrm{Cl})^{\mathrm{a}}$ & n (\%) & OR $(95 \% \mathrm{Cl})$ & $\operatorname{aOR}(95 \% \mathrm{Cl})^{\mathrm{a}}$ \\
\hline Untreated & $97 / 266(36.5)$ & $3.34(2.17,5.16)^{b, c}$ & $1.79(1.12,2.87)^{c}$ & 17/261 (6.5) & $2.62(1.06,6.48)^{c}$ & $1.36(0.52,3.55)$ \\
\hline Alemtuzumab & $3 / 30(10.0)$ & $0.70(0.20,2.47)$ & $0.86(0.24,3.07)$ & $1 / 30(3.3)$ & $1.41(0.16,12.09)$ & $1.93(0.22,16.77)$ \\
\hline Cladribine & $2 / 27(7.4)$ & $0.60(0.13,2.72)$ & $0.67(0.14,3.16)$ & $0 / 27(0.0)$ & - & - \\
\hline Dimethyl fumarate & $38 / 268(14.2)$ & 1.00 (Ref) & 1.00 (Ref) & $7 / 259(2.7)$ & 1.00 (Ref) & 1.00 (Ref) \\
\hline Fingolimod & 16/195 (8.2) & $0.60(0.32,1.11)$ & $0.64(0.34,1.21)$ & 4/193 (2.1) & $0.80(0.23,2.79)$ & $0.90(0.25,3.19)$ \\
\hline Glatiramer acetate & 16/86 (18.6) & $1.36(0.71,2.61)$ & $1.06(0.53,2.10)$ & $0 / 86(0.0)$ & - & - \\
\hline Interferon & $17 / 119$ (14.3) & $1.11(0.59,2.11)$ & $0.89(0.46,1.70)$ & $2 / 118(1.7)$ & $0.62(0.13,3.10)$ & $0.54(0.11,2.73)$ \\
\hline Natalizumab & $24 / 212(11.3)$ & $0.84(0.48,1.46)$ & $0.82(0.47,1.45)$ & $6 / 209(2.9)$ & $1.07(0.35,3.25)$ & $1.11(0.36,3.43)$ \\
\hline Ocrelizumab & $116 / 463(25.1)$ & $2.14(1.41,3.24)^{\mathrm{b}, \mathrm{c}}$ & $1.56(1.01,2.41)^{c}$ & $37 / 463(8.0)$ & $3.00(1.30,6.89)^{c}$ & $2.30(0.98,5.39)$ \\
\hline Rituximab & $70 / 252(27.8)$ & $3.12(1.92,5.07)^{\mathrm{b}, \mathrm{c}}$ & $2.43(1.48,4.02)^{\mathrm{b}, \mathrm{c}}$ & 24/251 (9.6) & $4.63(1.86,11.49)^{b, c}$ & $3.93(1.56,9.89)^{b, c}$ \\
\hline Teriflunomide & 14/93 (15.1) & $1.21(0.61,2.38)$ & $0.85(0.42,1.72)$ & 4/93 (4.3) & $1.59(0.45,5.59)$ & $1.15(0.32,4.14)$ \\
\hline \multirow[t]{3}{*}{ Other DMT } & $16 / 68(23.5)$ & $2.09(1.07,4.09)^{c}$ & $1.10(0.54,2.24)$ & $4 / 67(6.0)$ & $2.34(0.66,8.33)$ & $1.27(0.34,4.72)$ \\
\hline & \multicolumn{3}{|l|}{ Ventilation } & \multicolumn{3}{|l|}{ Death } \\
\hline & n (\%) & OR $(95 \% \mathrm{Cl})$ & $\operatorname{aOR}(95 \% \mathrm{CI})^{\mathrm{a}}$ & n (\%) & OR $(95 \% \mathrm{Cl})$ & aOR $(95 \% \mathrm{CI})^{\mathrm{a}}$ \\
\hline Untreated & 18/261 (6.9) & $2.51(1.00,6.26)^{c}$ & $1.31(0.49,3.49)$ & $27 / 261(10.3)$ & $5.69(2.13,15.19)^{\mathrm{b}, \mathrm{c}}$ & $1.64(0.56,4.80)$ \\
\hline Alemtuzumab & $1 / 30(3.3)$ & $0.98(0.11,8.63)$ & $1.27(0.14,11.34)$ & $1 / 30(3.3)$ & $2.10(0.23,19.15)$ & $2.11(0.19,23.29)$ \\
\hline Cladribine & $0 / 27(0.0)$ & - & - & $0 / 27(0.0)$ & - & - \\
\hline Dimethyl fumarate & $7 / 259(2.7)$ & 1.00 (Ref) & 1.00 (Ref) & $5 / 259(1.9)$ & 1.00 (Ref) & 1.00 (Ref) \\
\hline Fingolimod & $5 / 193(2.6)$ & $0.76(0.23,2.50)$ & $0.79(0.24,2.67)$ & $0 / 193(0.0)$ & - & - \\
\hline Glatiramer acetate & $0 / 86(0.0)$ & - & - & $2 / 86(2.3)$ & $1.05(0.20,5.57)$ & $0.56(0.10,3.25)$ \\
\hline Interferon & $1 / 118(0.8)$ & $0.21(0.02,1.75)$ & $0.18(0.02,1.52)$ & $1 / 118(0.8)$ & $0.58(0.07,5.20)$ & $0.31(0.03,2.82)$ \\
\hline Natalizumab & $4 / 209$ (1.9) & $0.74(0.21,2.59)$ & $0.72(0.20,2.55)$ & $3 / 209$ (1.4) & $0.78(0.18,3.33)$ & $0.72(0.16,3.30)$ \\
\hline Ocrelizumab & 18/463 (3.9) & $1.48(0.60,3.66)$ & $1.04(0.41,2.64)$ & $12 / 463(2.6)$ & $1.22(0.42,3.56)$ & $0.49(0.16,1.52)$ \\
\hline Rituximab & $24 / 251(9.6)$ & $5.11(2.01,12.99)^{b, c}$ & $4.00(1.54,10.39)^{c}$ & $7 / 251(2.8)$ & $2.61(0.76,8.96)$ & $1.22(0.35,4.18)$ \\
\hline Teriflunomide & $4 / 93(4.3)$ & $1.33(0.37,4.79)$ & $0.83(0.22,3.10)$ & $1 / 93(1.1)$ & $0.59(0.07,5.21)$ & $0.27(0.03,2.53)$ \\
\hline Other DMT & $2 / 67(3.0)$ & $1.12(0.22,5.71)$ & $0.61(0.12,3.21)$ & $4 / 67(6.0)$ & $3.82(0.97,15.00)$ & $1.05(0.25,4.45)$ \\
\hline
\end{tabular}

Abbreviations: $\mathrm{aOR}=$ adjusted OR; $\mathrm{Cl}$ = confidence interval; COVID-19 = coronavirus disease 2019; DMT = disease-modifying therapy; EDSS = Expanded Disability Status Scale; ICU = intensive care unit; OR = odds ratio; Ref = referent.

Analysis by multilevel mixed-effects logistic regression estimating OR $(95 \% \mathrm{CI})$.

${ }^{a}$ Multivariable models adjusted for age, sex, multiple sclerosis phenotype, and EDSS score.

${ }^{\text {b }}$ Significant after family-wise Holm step-down multiple-comparisons adjustment. Other DMT was queried as on another drug not listed plus siponimod.

' Statistical significance $(p<0.05)$.

pooled other DMTs, while the untreated were typically older, had progressive MS phenotype, and had higher disability.

\section{COVID-19 Severity by Clinical/Demographic Characteristics}

Demographic and clinical characteristics of hospitalization and ICU admission (eTable 1, links.lww.com/WNL/B520) and need for artificial ventilation and death (eTable 2, links.lww. com/WNL/B521) among suspected/confirmed COVID-19 cases were assessed. In multivariable models, male sex was associated with $61 \%$ and $92 \%$ greater risks of hospitalization and death, while older age was positively associated with hospitalization and death. Progressive MS phenotype was associated with $68 \%$ higher risk of hospitalization. Higher EDSS score was associated with higher risks of all outcomes, including 279\% higher hospitalization, $211 \%$ higher ICU admission, $281 \%$ higher ventilation, and $893 \%$ higher death frequencies. Among confirmed-only COVID-19, all associations persisted except for age $>70$ years, which became nonsignificant (data not shown). 


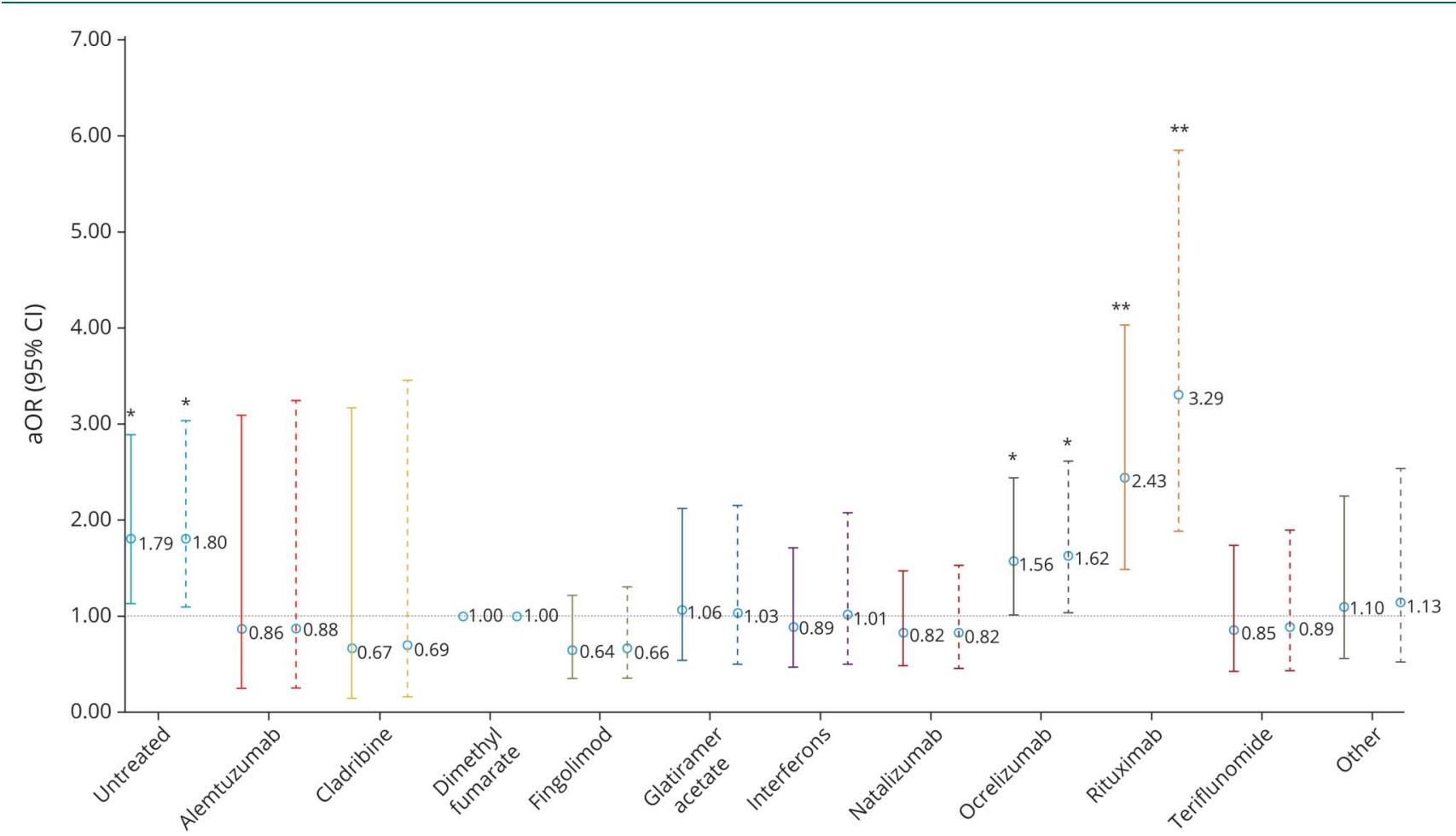

Disease-modifying therapies (DMTs) compared to dimethyl fumarate adjusted for age, sex, multiple sclerosis phenotype, and Expanded Disability Status Scale score. Other DMTs also include siponimod. aOR = adjusted odds ratio; $\mathrm{Cl}=$ confidence interval. ${ }^{*} p<0.05,{ }^{*} p<0.001$.

In the subset of data sources with data (comorbid conditions $84.2 \%$, BMI $55.6 \%$, smoking $79.3 \%$ ), having one of the specified comorbid conditions queried showed a positive trend with increased risk of death (adjusted OR [aOR] 2.91), while obese BMI had a $152 \%$ higher risk of hospitalization, 312\% higher risk of ICU admission, and $445 \%$ higher risk of requiring ventilation. Smoking was not associated with any outcomes.

Adjustment for multiple comparisons found most associations of sex, age, MS phenotype, and EDSS score with COVID-19 outcomes persisted, as did BMI and comorbid conditions.

\section{COVID-19 Severity by DMT}

Compared to dimethyl fumarate, rituximab use was associated with greater risks of hospitalization (aOR 2.43, 95\% confidence interval $[\mathrm{CI}] 1.48,4.02$ ), ICU admission (aOR 3.93, 95\% CI 1.56, 9.89), and artificial ventilation (aOR 4.00, 95\% CI 1.54, 10.39, Table 2). Ocrelizumab showed similar associations for hospitalization (aOR 1.56, 95\% CI 1.01, 2.41) and ICU admission (aOR 2.30, 95\% CI 0.98, 5.39) but not artificial ventilation (aOR 1.04, 95\% CI 0.41, 2.64).

No DMTs were associated with death. Untreated patients had increased risk of hospitalization (aOR 1.79, 95\% CI 1.12, 2.87), but no independent associations with other outcomes were seen. These associations persisted among confirmed-only COVID-19 (Figures 2-4). Moreover, even on comparison to DMTs other than dimethyl fumarate as a post hoc analysis, rituximab consistently showed stronger associations with outcomes than ocrelizumab for hospitalization and ICU admission and was solely associated with requiring artificial ventilation (data not shown).

On adjustment for multiple comparisons, among suspected plus confirmed cases, rituximab associations with hospitalization and ICU admission remained significant, although that for ventilation did not. However, among confirmed-only cases, the rituximab associations with hospitalization, ICU admission, and need for artificial ventilation remained significant after multiple-comparisons adjustment. The association of ocrelizumab with increased hospitalization did not remain significant in any analysis.

\section{COVID-19 Severity: Anti-CD20 DMTs vs Pooled Other DMTs}

Compared to all other DMTs, those using rituximab had higher risks of hospitalization (aOR 2.76, 95\% CI 1.87, 4.07, Table 3), ICU admission (aOR 4.32, 95\% CI 2.27, 8.23), and artificial ventilation (aOR 6.15, 95\% CI 3.09, 12.27). Ocrelizumab showed similar trends for hospitalization (aOR 1.75, 95\% CI 1.29, 2.38) and ICU admission (aOR 2.55, 95\% CI $1.49,4.36$ ) but not ventilation (aOR 1.60, 95\% CI 0.82-3.14). Neither rituximab (aOR 1.72, 95\% CI 0.58, 5.10) or ocrelizumab $(\mathrm{aOR}=0.73,95 \% \mathrm{CI}=0.32,1.70)$ was associated with risk of death. Untreated patients had increased risks of hospitalization (aOR 2.05, 95\% CI 1.43, 2.94), ventilation (aOR 


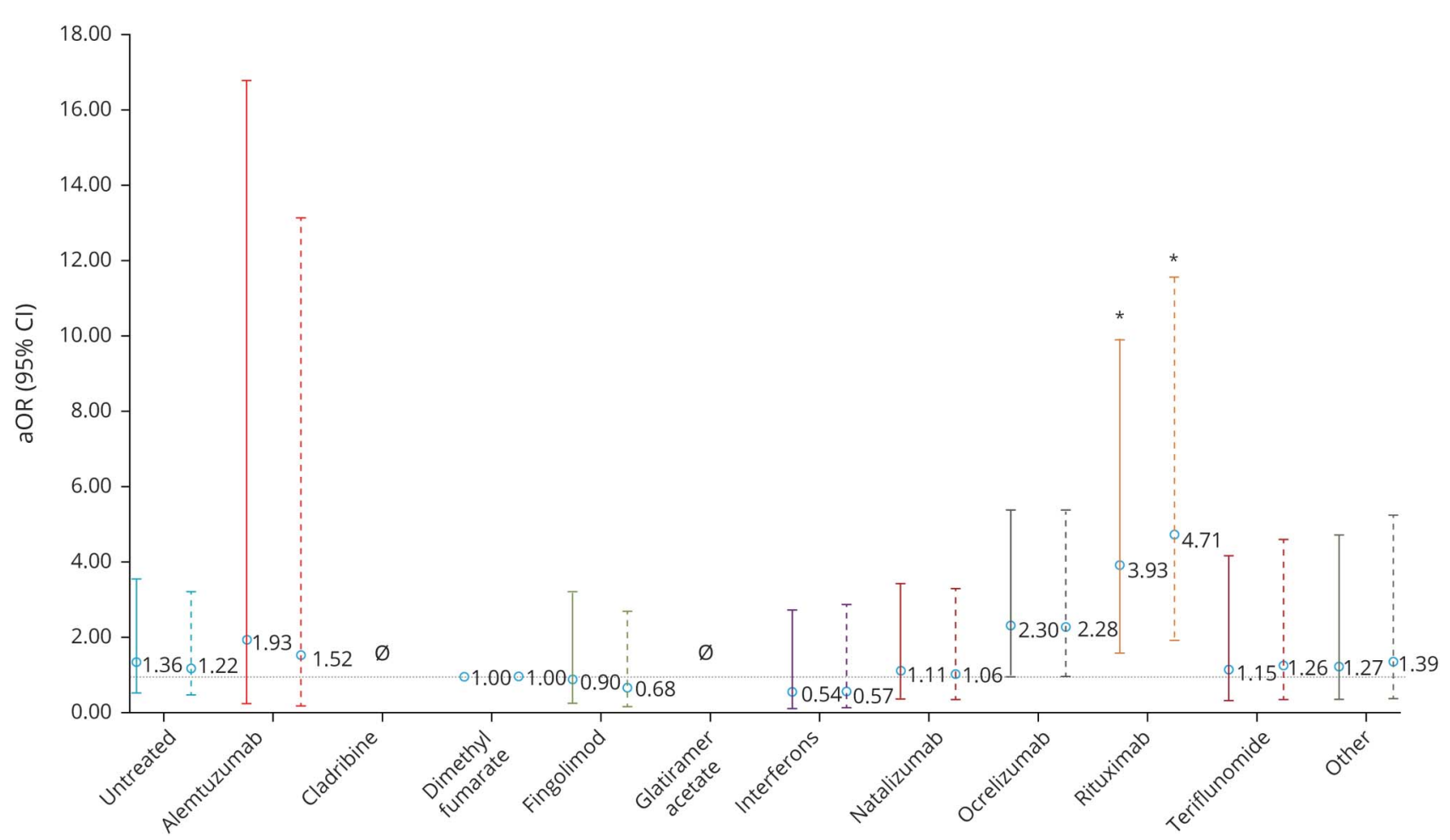

Disease-modifying therapies (DMTs) were compared to dimethyl fumarate, adjusted for age, sex, multiple sclerosis phenotype, and Expanded Disability Status Scale score. Other DMTs also include siponimod. Null set denotes analyses that could not be undertaken due to no events occurring in the exposed group. $\mathrm{aOR}=$ adjusted odds ratio; $\mathrm{Cl}=$ confidence interval. ${ }^{*} p<0.05$.

2.07, 95\% CI 1.01.4.22), and death (aOR 2.53, 95\% CI 1.24.5.15). These results persisted among confirmed-only COVID-19 cases (data not shown).

After adjustment for multiple comparisons, all rituximab and ocrelizumab associations persisted, while that for the untreated patients persisted for hospitalization and death. Among confirmed-only cases, rituximab associations remained significant after multiple-comparisons adjustment, while that for ocrelizumab persisted only for hospitalization and for untreated for hospitalization and ventilation.

\section{COVID-19 Severity, Anti-CD20 DMTs vs Natalizumab}

Compared to natalizumab, rituximab was associated with higher risks of hospitalization (aOR 2.88, 95\% CI 1.68.4.92), ICU admission (aOR 3.23, 95\% CI 1.17.8.91), and ventilation (aOR 5.52, 95\% CI 1.71.17.84). Ocrelizumab showed similar trends for hospitalization (aOR 1.86, 95\% CI 1.13.3.07) but did not reach significance for ICU admission and was not associated with ventilation. Neither rituximab (aOR 1.34, 95\% CI 0.27.6.56) nor ocrelizumab (aOR 0.48, 95\% CI 0.11.2.07) was associated with increased risk of death. Results were similar among confirmed-only COVID19 (data not shown).
On adjustment for multiple comparisons, rituximab associations with hospitalization, ICU admission, and need for artificial ventilation all persisted, while that for ocrelizumab persisted only for hospitalization. On restriction to confirmedonly cases, this was also seen.

\section{Stratification Sensitivity Analyses}

To assess whether the associations seen for ocrelizumab and rituximab were genuinely a function of the DMTs rather than the characteristics of patients commonly treated with these medications (older, progressive MS, higher disability), we undertook stratified analyses evaluating associations between DMTs and hospitalization, ICU admission, need for artificial ventilation, and death among persons $>70$ vs $\leq 70$ years of age, among those with RRMS vs progressive, and among patients with EDSS scores $\leq 6$ vs $>6$. By age, ocrelizumab and rituximab associations with outcomes were seen only among those $\leq 70$ years of age. By MS phenotype, ocrelizumab and rituximab consistently showed that associations with outcomes were roughly 2 to 3 times stronger in magnitude among those with the RRMS phenotype. By EDSS score, ocrelizumab and rituximab associations with hospitalization were roughly comparable, but associations with ICU admission and ventilation were 2 to 3 times stronger in magnitude among those of EDSS score $\leq 6$. These results indicate that the observed associations were a 


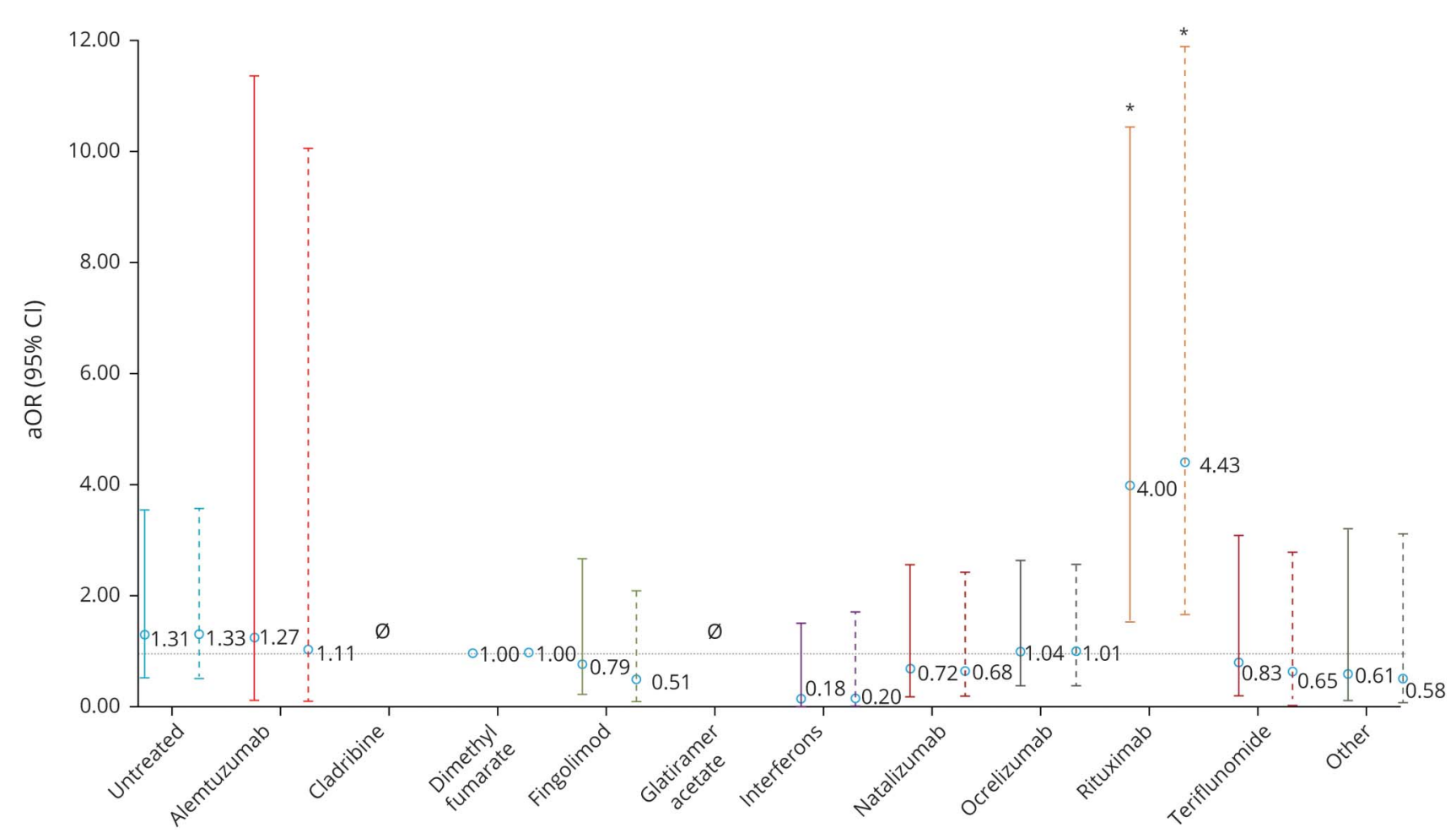

Disease-modifying therapies (DMTs) were compared to dimethyl fumarate adjusted for age, sex, multiple sclerosis phenotype, and Expanded Disability Status Scale score. Other DMTs also includes siponimod. Null set denotes analyses that could not be undertaken due to no events occurring in the exposed group. $\mathrm{aOR}=$ adjusted odds ratio; $\mathrm{Cl}=$ confidence interval. ${ }^{*} p<0.05$.

function of the DMT, not the underlying risk profile (data not shown).

\section{Discussion}

In the largest sample of people with MS with suspected and confirmed COVID-19 to date, we demonstrated that the antiCD20 DMTs rituximab and ocrelizumab were associated with more severe COVID-19. Compared to dimethyl fumarate, pooled other DMTs, and natalizumab, anti-CD20 DMTs were associated with higher risks of hospitalization and ICU admission, while only rituximab was associated with greater risk of requiring artificial ventilation. Comparison to natalizumab is particularly important, showing that anti-CD20 associations do not likely reflect ascertainment bias. Regardless of comparator, rituximab consistently showed stronger associations with outcomes than ocrelizumab for hospitalization and ICU admission and was solely associated with requiring artificial ventilation. It is important to note that this was done as a post hoc exploration, not an a priori plan, given the specific hypotheses of the study. At the same time, untreated patients had a significantly greater risk of death compared to persons treated with dimethyl fumarate and pooled non-anti-CD20 DMTs, although this attenuated markedly on adjustment. Moreover, DMT associations were not merely driven by older age, progressive MS phenotype, or higher disability. We also found that older age, progressive MS phenotype, and higher disability were overrepresented among patients with MS with more severe COVID-19. In subanalyses in which data were available, DMT associations were robust to further adjustment for comorbid conditions, BMI, and smoking status. Results were generally consistent on adjustment for multiple comparisons.

An increasing array of highly effective DMTs with heterogeneous modes of effect have become available for people with MS but can increase infection risk. ${ }^{1,11}$ This has raised concern during the COVID-19 pandemic, and national studies have investigated risk factors for severe COVID-19 disease in people with MS. In the French Covisep study, ${ }^{3}$ of 347 patients with MS (42.1\% confirmed COVID-19), older age, progressive MS phenotype, higher disability, and comorbid conditions were associated with COVID-19 severity. The authors' pooled DMTs with moderate/high risk of systemic infection (fingolimod/ ocrelizumab/rituximab/cladribine/alemtuzumab) were associated with 4.2 times higher COVID-19 severity score than DMTs with no systemic infection risk (interferon beta/glatiramer acetate). This amalgamation of DMTs is a limitation because, while comparable in terms of their infection risk, these DMTs have markedly different modes of action, especially in relation to the immunologic response to SARS-CoV-2. ${ }^{10}$ More recently, the Italian MuSC-19 national registry study of 593 suspected and 
Table 3 Characteristics of COVID-19 Severity Outcomes, Anti-CD20 DMTs vs All Other DMTs, and Anti-CD20 DMTs vs Natalizumab, Suspected Plus Confirmed COVID-19

\begin{tabular}{|c|c|c|c|c|c|c|}
\hline & \multicolumn{3}{|l|}{ Hospitalization } & \multicolumn{3}{|l|}{ ICU admission } \\
\hline & n (\%) & OR $(95 \% \mathrm{CI})$ & $\operatorname{aOR}(95 \% \mathrm{CI})^{\mathrm{a}}$ & n (\%) & OR $(95 \% \mathrm{Cl})$ & $\operatorname{aOR}(95 \% \mathrm{Cl})^{\mathrm{a}}$ \\
\hline Pooled other DMT & $144 / 1,082(13.3)$ & 1.00 (Ref) & 1.00 (Ref) & 28/1,082 (2.6) & 1.00 (Ref) & 1.00 (Ref) \\
\hline Ocrelizumab & $116 / 463(25.1)$ & $2.15(1.62,2.87)^{b, c}$ & $1.75(1.29,2.38)^{\mathrm{b}, \mathrm{c}}$ & $37 / 463(8.0)$ & $3.08(1.83,5.17)^{\mathrm{b}, \mathrm{c}}$ & $2.55(1.49,4.36)^{\mathrm{b}}$ \\
\hline Rituximab & $70 / 251$ (27.9) & $3.16(2.17,4.61)^{\mathrm{b}, \mathrm{c}}$ & $2.76(1.87,4.07)^{\mathrm{b}, \mathrm{c}}$ & $24 / 251(9.6)$ & $4.69(2.49,8.83)^{b, c}$ & $4.32(2.27,8.23)^{\mathrm{b}, \mathrm{c}}$ \\
\hline No DMT & $97 / 261(37.2)$ & $3.49(2.54,4.80)^{\mathrm{b}, \mathrm{c}}$ & $2.05(1.43,2.94)^{\mathrm{b}, \mathrm{c}}$ & $17 / 261(6.5)$ & $2.69(1.43,5.04)^{b, c}$ & $1.52(0.77,3.02)$ \\
\hline Natalizumab & $24 / 209$ (11.5) & 1.00 (Ref) & 1.00 (Ref) & $6 / 209(2.9)$ & 1.00 (Ref) & 1.00 (Ref) \\
\hline Ocrelizumab & $116 / 463(25.1)$ & $2.64(1.64,4.25)^{\mathrm{b}, \mathrm{c}}$ & $1.86(1.13,3.07)^{b, c}$ & $37 / 463(8.0)$ & $2.89(1.18,7.05)^{b, c}$ & $2.13(0.85,5.35)$ \\
\hline \multirow[t]{3}{*}{ Rituximab } & $70 / 251(27.9)$ & $3.16(1.89,5.26)^{\mathrm{b}, \mathrm{c}}$ & $2.88(1.68,4.92)^{b, c}$ & $24 / 251(9.6)$ & $4.17(1.55,11.18)^{b, c}$ & $3.23(1.17,8.91)^{\mathrm{b}, \mathrm{c}}$ \\
\hline & \multicolumn{3}{|l|}{ Ventilation } & \multicolumn{3}{|l|}{ Death } \\
\hline & n (\%) & OR $(95 \% \mathrm{Cl})$ & $\operatorname{aOR}(95 \% \mathrm{Cl})^{\mathrm{a}}$ & n (\%) & OR $(95 \% \mathrm{Cl})$ & $\operatorname{aOR}(95 \% \mathrm{Cl})^{a}$ \\
\hline Pooled other DMT & $24 / 1,082(2.2)$ & 1.00 (Ref) & 1.00 (Ref) & 17/1,082 (1.6) & 1.00 (Ref) & 1.00 (Ref) \\
\hline Ocrelizumab & $18 / 463(3.9)$ & $1.99(1.04,3.80)^{\mathrm{b}, \mathrm{c}}$ & $1.60(0.82,3.14)$ & $12 / 463(2.6)$ & $1.38(0.65,2.96)$ & $0.76(0.34,1.69)$ \\
\hline Rituximab & $24 / 251(9.6)$ & $6.95(3.54,13.64)^{b, c}$ & $6.15(3.09,12.27)^{b, c}$ & $7 / 251(2.8)$ & $2.94(1.12,7.72)^{\mathrm{c}}$ & $1.90(0.73,4.93)$ \\
\hline No DMT & $18 / 261(6.9)$ & $3.42(1.78,6.57)^{\mathrm{b}, \mathrm{c}}$ & $2.07(1.01,4.22)^{c}$ & $27 / 261(10.3)$ & $6.47(3.40,12.33)^{\mathrm{b}, \mathrm{c}}$ & $2.53(1.24,5.15)^{\mathrm{b}, \mathrm{c}}$ \\
\hline Natalizumab & $4 / 209$ (1.9) & 1.00 (Ref) & 1.00 (Ref) & $3 / 209(1.4)$ & 1.00 (Ref) & 1.00 (Ref) \\
\hline Ocrelizumab & $18 / 463(3.9)$ & $2.11(0.69,6.39)$ & $1.34(0.42,4.24)$ & $12 / 463(2.6)$ & $1.64(0.45,5.96)$ & $0.53(0.13,2.24)$ \\
\hline Rituximab & 24/251 (9.6) & $7.52(2.37,23.81)^{b, c}$ & $5.52(1.71,17.84)^{b, c}$ & $7 / 251(2.8)$ & $2.96(0.66,13.29)$ & $1.70(0.38,7.62)$ \\
\hline
\end{tabular}

Abbreviations: aOR = adjusted OR; CI = confidence interval; COVID-19 = coronavirus disease 2019; DMT = disease-modifying therapy; EDSS = Expanded Disability Status Scale; ICU = intensive care unit; OR = odds ratio; Ref = referent.

Analysis by multilevel mixed-effects logistic regression estimating OR $(95 \% \mathrm{CI})$. Other DMT was queried as on another drug not listed, as well as aggregated with Siponimod, due to infrequency of persons on this DMT.

${ }^{a}$ Multivariable models adjusted for age, sex, multiple sclerosis phenotype, and EDSS score.

${ }^{b}$ Significant after family-wise Holm step-down multiple-comparisons adjustment.

c Statistical significance $(p<0.05)$.

191 confirmed COVID-19 cases found that anti-CD20 DMT use was associated with 2.6 times greater risk of severe COVID19 compared to dimethyl fumarate use, adjusted for region, age, sex, MS phenotype, and recent methylprednisolone use. ${ }^{5}$ Finally, the COViMS study found that, compared to untreated patients, rituximab- and ocrelizumab-treated patients had 4.6 and 1.6 times greater odds of hospitalization, although no significant associations were seen for other outcomes. ${ }^{2}$ This disparity with our and previous results may reflect their use of the untreated as the comparator, as well as differences in the multivariable model covariates. It should be acknowledged that the COViMS sample comprised a meaningful proportion of our total sample ( $\mathrm{n}=$ 1,161 of 2,340,49.6\%), and while the total cohort analyzed and analysis methods used here differ, results for this cohort have been described previously. The remainder of the cohort described here has not been previously described.

Indeed, the issue of comparator is a point of particular attention in our study; we compared individual DMTs to dimethyl fumarate, and then, because they showed significant associations here, the anti-CD20 DMTs were compared against all other DMTs, and finally these were compared to natalizumab. Dimethyl fumarate was identified as a suitable comparator, being common in the sample and also used for the MuSC-19 study. ${ }^{5}$ The untreated were not regarded as an appropriate primary comparator because these patients differed markedly from the rest of the cohort in age, disability, and MS phenotype. This latter comparator is of particular importance because it assesses ascertainment bias as a potential explanation for the associations seen for anti-CD20 DMTs. Both the anti-CD20 DMTs and natalizumab require patients to come in for DMT infusion at 6- and 3-month intervals, respectively. Thus, if the anti-CD20 DMT associations with COVID-19 severity were merely a function of more regular hospital attendance and thus potential for COVID-19 symptoms to be identified and treatment initiated, then there should be no difference from natalizumab. In fact, we found that the associations of ocrelizumab and rituximab with hospitalization and ICU admission and rituximab with need for artificial ventilation persist.

Untreated patients showed consistent positive trends toward associations with hospitalization, ICU admission, and requiring ventilation, albeit attenuating on adjustment for age, 
sex, MS phenotype, and disability. This is in keeping with prior results. Louapre et $\mathrm{al}^{3}$ found higher frequencies of severe COVID-19 among the untreated vs treated ( $46.0 \%$ vs $15.5 \%$ ), although this difference did not persist on adjustment. Sormani et al. ${ }^{5}$ compared untreated to dimethyl fumarate-treated patients, finding that they were 2.83 times more likely to have severe COVID-19, although this disappeared on adjustment (aOR 1.04). The lack of independence of the untreated associations here and previously likely reflects the untreated comprising, to variable degrees, people with a more benign MS course or other reasons not to use DMTs, so adjustment for MS phenotype and disability largely captures differences in COVID-19 severity. That said, it is important to acknowledge that the heterogeneity of this patient population may extend beyond differences in clinical phenotype and likely includes a range of patient and region-level idiosyncrasies for which we were unable to account.

The directions of effect in the associations of rituximab and ocrelizumab were consistent for the hospitalization and ICU admission outcomes, although those for rituximab were stronger and only rituximab showed an association with requiring artificial ventilation. It is possible that differences in biology, due to differences in provenance or affinity for the CD20 protein ${ }^{12,13}$ or differences in mechanisms of cytotoxicity, ${ }^{14}$ may underlie some of this difference. More likely, these differences represent unmeasured confounding because the dataset, while large, was limited in the number of characteristics assessed, so potentially relevant factors like socioeconomic status and access to care or factors affecting respiratory health could not be assessed. In addition, parameters such as time on treatment or serum immunoglobulin load, which would have been valuable to explore for explanations for differences in associations between these 2 DMTs, were not available. That said, there was general internal consistency, and our results are broadly in line with those seen in other studies, ${ }^{3,5}$ providing external consistency. This preliminary observation is worth exploring in laboratory studies.

That anti-CD20 DMTs were not associated with death conflicts with the results seen for the other outcomes, as well as with the MuSC-19 study, which found a positive trend between anti-CD20 DMTs and death. The issue may lie in ascertainment bias, with fewer of the older patients included in our sample: we had only $9.1 \%$ of confirmed COVID-19 cases $>60$ years of age vs $17.7 \%$ in the MuSC- 19 cohort. $^{5}$ It is also possible that the infrequency of deaths in our cohort ( $\mathrm{n}=$ $73,3.2 \%$ ) may have limited our statistical power to assess this relationship. That said, our number of deaths was actually greater than in previous studies $(\mathrm{n}=12-54)$, and we did demonstrate similar deleterious associations of older age and higher disability with death seen previously. ${ }^{2,3,5}$ The potential impacts of these DMTs on death caused by COVID-19 should be further explored.

In contrast to prior clinic-based studies, our cohort focused on a predefined limited set of demographic and clinical characteristics. ${ }^{6}$
Thus, we could not assess other clinical features, particularly prior MS clinical course and DMT use, paraclinical information such as radiologic burden of MS, or the nuanced details of COVID-19 onset and evolution. Another limitation of our data is that they likely comprise greater proportions of severe cases requiring medical attention. One particular element lacking in our data is treatment duration or duration since treatment; both may have bearing on the degree of B-cell depletion and thus on COVID-19 severity. This information was included in the core questionnaire, but the level of missingness was too high to be a component of analyses. These data would have been useful in better describing and explaining the differences in the associations between rituximab and ocrelizumab, but unfortunately, this information was not available here. In addition, data on steroid use and other DMTs that might have affected clinical progression or resulted in less severe COVID-19 were not available.

Heterogeneity in the definitions of exposure and outcomes and in patient inclusion among the data sources is a known problem in combining multiple data sources. Related to this are the differences in protocols for hospital and ICU admission and initiation of artificial ventilation between hospitals, as well as differences in the availability/use of DMTs between countries. ${ }^{15}$ To ensure that our results were not being driven by single influential data sources, we undertook all analyses using random-effects logistic regression, as well as serial-exclusion sensitivity analyses. These analyses showed that, while there was some variation in the magnitudes and significance of associations, trends tracked as seen for the whole cohort, indicating that the results were not driven by a specific data source.

Another issue lies in the anonymous nature of the data entry, such that patients may be entered more than once in different data sources. We are unable to account for whether participants already participated or had their data entered in another study because there is no identifying information to assess this or any query of prior participation in the survey.

Another issue is the nature of the data aggregation, with some data sources providing individual patient-level data but others only tabulations of discrete categorical terms. Thus, we were obliged to use 3-level categories of age, 2-level EDSS scores, and 2-level BMIs rather than more exact values of each or 2-level MS phenotype (RRMS/progressive) rather than individual MS phenotype (RRMS/secondary progressive MS/ primary progressive MS). That said, these levels are generally aligned with the levels of each associated with increased COVID-19 severity.

This data aggregation process and resultant limitation of the number of dimensions of model covariates thus required a somewhat simplified definition of underlying clinical severity as used in the stratified analyses by age, MS phenotype, and disability. We are also limited in not having additional clinical detail such as relapse activity or MRI parameters, which would have allowed greater depth of assessment of underlying 
disease risk phenotype. That said, older age, progressive MS phenotype, and higher disability have been consistently demonstrated as risk factors for COVID-19 severity across our results and previous studies, ${ }^{2,3,5}$ so if the DMT associations were merely a function of underlying clinical susceptibility, it should be expected that analyses stratified by these covariates would show some signal. That they did not is indicative of a true association.

The information collected through the different sources does not provide us with detailed information about validation of the COVID-19 diagnosis. Whether patients remained in the suspected group because of discrepancy between clinical and laboratory assessment or other reasons is unknown. Because of these diagnostic uncertainties, we opted to perform 2 analyses, 1 among group with suspected and confirmed COVID-19 and 1 in confirmed COVID-19 only.

Another potential issue is the representativeness of the included patients from each of the noncentral data sources. While there were no inclusion or exclusion criteria beyond the patients needing to have MS and be at least 18 years of age, the clinicians entering data for their patients would likely bias to enter data on patients who had suspected or confirmed COVID-19; this was reflected in the low proportion of the sample without suspected/confirmed COVID-19 (data not shown). However, such bias is typical of all the clinic-based studies of this sort. Our cohort characteristics are typical of people with MS, including female, RRMS phenotype, and low disability preponderance, so the extent to which this generalizability may affect the analyses here is likely minimal.

The fact that inverse trends were seen for smoking status and COVID-19 is puzzling and not in line with expectations of a deleterious association with a respiratory condition. The frequency of current smokers in the cohort is low compared to other cohorts, ${ }^{16-18}$ which may account for the absence of associations. In addition, smoking status was not available from all data sources, so a material proportion (20.7\%) of the sample had smoking status missing. The Covisep study ${ }^{3}$ also found an inverse trend with COVID-19 severity, and the COViMS study ${ }^{2}$ found no associations. The explanation for this absence of a deleterious impact of smoking on COVID-19 severity may bear exploration.

In the largest population yet studied, we have shown that patients with MS treated with the anti-CD20 DMTs rituximab and ocrelizumab are at higher risk of more severe COVID-19 compared to those treated with dimethyl fumarate, pooled other DMTs, and natalizumab. This risk is additional to the risk associated with demographic and clinical characteristics, with older age, progressive MS phenotype, and higher disability all showing deleterious relationships with COVID-19 severity. These results agree with smaller cohort studies and suggest that the risk vs benefit of continued or new exposure to CD20-depleting treatment strategies compared to other DMTs needs to be considered in the context of the ongoing COVID-19 pandemic.

\section{Study Funding}

The authors disclosed receipt of the following financial support for the research, authorship, and/or publication of this article. The operational costs linked to this study are funded by the Multiple Sclerosis International Federation (MSIF) and the Multiple Sclerosis Data Alliance (MSDA), acting under the umbrella of the European Charcot Foundation. The MSDA receives income from a range of corporate sponsors, recently including Biogen, Bristol-Myers Squibb (formerly Celgene), Canopy Growth Corp, Genzyme, Icometrix, Merck, Mylan, Novartis, QMENTA, Quanterix, and Roche. MSIF receives income from a range of corporate sponsors, recently including Biogen, Bristol-Myers Squibb (formerly Celgene), Genzyme, Med-Day, Merck, Mylan, Novartis, and Roche. This work was supported by the Flemish government under the Onderzoeksprogramma Artificiële Intelligentie Vlaanderen programme and the Research Foundation Fladers (FWO) for ELIXIR Belgium-Flanders (FWO) for ELIXIR Belgium. The central platform was provided by QMENTA, and the computational resources used in this work were provided by Amazon. The statistical analysis was carried out at CORe, The University of Melbourne, with support from the National Health and Medical Research Council (NHMRC; 1129189 and 1140766).

\section{Disclosure}

T. Kalincik has served on scientific advisory boards for Roche, Sanofi-Genzyme, Novartis, Merck, and Biogen; served on a steering committee for Brain Atrophy Initiative by SanofiGenzyme; received conference travel support and/or speaker honoraria from WebMD Global, Novartis, Biogen, SanofiGenzyme, Teva, BioCSL, and Merck; and received research support from Biogen. N. Rijke and C. Walton have no personal pecuniary interests to disclose other than being employees of MSIF, which receives income from a range of corporate sponsors, recently including Biogen, BristolMyersSquibb (formerly Celgene), Genzyme, Med-Day, Merck, Mylan, Novartis, and Roche. J. Hillert has received honoraria for serving on advisory boards for Biogen, Celgene, SanofiGenzyme, Merck KGaA, Novartis, and Sandoz and speaker fees from Biogen, Novartis, Merck KGaA, Teva, and SanofiGenzyme; he has served as principal investigator for projects or received unrestricted research support from Biogen, Celgene, Merck KGaA, Novartis, Roche, and Sanofi-Genzyme; and his MS research was funded by the Swedish Research Council and the Swedish Brain foundation. G. Edan has received consulting/speaking fees and research support from Bayer, Novartis, Teva, Sanofi Genzyme, Merck Serono, Biogen Idec, and Roche. T. Spelman has served on scientific advisory boards for Biogen. R. McBurney and H. Schmidt work for the Accelerated Cure Project for MS (ACP), which has received grants, collaboration funding, payments for use of assets, or in-kind contributions from the following companies: EMD Serono, Sanofi/Genzyme, Biogen, Genentech, AbbVie, Octave, GlycoMinds, Pfizer, MedDay, AstraZeneca, Teva, Mallinckrodt, MSDx, Regeneron Genetics Center, BC Platforms, and Celgene. ACP has also received funding from the Patient-Centered Outcomes Research Institute and the National MS Society. A. 
Glaser has received research support from Novartis. R. McBurney has received consulting payments from EMD Serono, which have been donated to ACP. A. Bergmann has received consulting fees from and is an advisory board/ speaker/other activities for NeuroTransData, and has worked on project management/clinical studies for and received travel expenses from Novartis and Servier. A. Stahmann has no personal pecuniary interests to disclose other than being the lead of the German MS-Registry, which receives (project) funding from a range of public and corporate sponsors, recently including the German Innovation Fund, the German MS Trust, Biogen, German MS Society, Celgene (BMS), Merck, Novartis, Roche, and Sanofi. R. Middleton has received no personal funding from any sources but works for the UK MS Register, which is funded by the UK MS Society and has received funding for specific projects from Novartis, Sanofi-Genzyme, and Merck KGaA. RJ. Fox has received personal consulting fees from Actelion, Biogen, Celgene, EMD Serono, Genentech, Immunic, Novartis, Sanofi, Teva, and TG Therapeutics; has served on advisory committees for Actelion, Biogen, Immunic, and Novartis; and has received clinical trial contract and research grant funding from Biogen and Novartis. A. van der Walt has received honoraria and unrestricted research funding from Novartis, Biogen, Roche, Merck, and Sanofi. H. Butzkueven's institution receives compensation for Advisory Board, Steering Committee, and educational activities from Biogen, Roche, Merck, and Novartis. His institution receives research support from Roche, Novartis, Biogen, NHMRC, MRFF Australia, MS Research Australia, and the Trish MS Foundation. He receives personal compensation from Oxford HPF for serving on the steering group of MS Brain Health. R. Alroughani received honoraria as a speaker for and for serving on scientific advisory boards from Bayer, Biogen, GSK, Merck, Novartis, Roche, and Sanofi-Genzyme. J.I. Rojas has received honoraria from Novartis as a scientific advisor and has received travel grants and attended courses and conferences on behalf of MerckSerono Argentina and Novartis Argentina. G. Sciascia do Olival has received honoraria for lecturing and support for congress participation from Biogen, Merck, Novartis, Sanofi/Genzyme, EMS, and Roche. M. Magyari has served on scientific advisory board for Biogen, Sanofi, Roche, Novartis, Merck, and Abbvie; has received honoraria for lecturing from Biogen, Merck, Novartis, Sanofi, and Genzyme; and has received research support and support for congress participation from Biogen, Genzyme, Roche, Merck, and Novartis. R. Alonso has received honoraria from Novartis as a scientific advisor and received travel grants and attended courses and conferences on behalf of Merck-Serono Argentina, Biogen Argentina, Genzyme Argentina, Roche Argentina, and Novartis Argentina. R. Nicholas has received honoraria from Novartis, Roche, and Biogen for advisory boards. A. Zabalza has received travel expenses for scientific meetings from Biogen, Novartis, and Genzyme; speaking honoraria from Eisai; and a study grant from Novartis. G. Arrambide has received compensation for consulting services or participation in advisory boards from Sanofi, Merck, and Roche; research support from Novartis; travel expenses for scientific meetings from Novartis, Roche, Stendhal, and
ECTRIMS; speaking honoraria from Sanofi and Merck; and is a member of the International Women in Multiple Sclerosis network executive committee. G. Comi has received consulting and speaking fees from Novartis, Teva Pharmaceutical Industries Ltd, Teva Italia Srl, Sanofi Genzyme, Genzyme Corp, Genzyme Europe, Merck KGgA, Merck Serono SpA, Celgene Group, Biogen Idec, Biogen Italia Srl, F. Hoffman-La Roche, Roche SpA, Almirall SpA, Forward Pharma, Medday, and Excemed. L.M. Peeters has no personal pecuniary interests to disclose other than being the chair of the MSDA, which receives income from a range of corporate sponsors, recently including Biogen, BristolMyersSquibb (formerly Celgene), Canopy Growth Corp, Genzyme, Icometrix, Merck, Mylan, Novartis, QMENTA, Quanterix, Roche. S. Simpson-Yap, E. De Brouwer, Y. Moreau, L. Geys, T. Parciak, C. Gautrais, N. Lazovski, A. Pirmani, A. Ardeshirdavanai , L.E. Forsberg, S. Braune, A. Salter, S. Ozakbas, I. van der Mei, N. Nag, R. Ivanov, A. Estavo Dias, D. Guimarães Brum, M.F. Mendes, J. Bauer, A.S. Chertcoff, and A. Fidao report no disclosures relevant to the manuscript. Go to Neurology.org/N for full disclosures.

\section{Publication History}

This manuscript was prepublished in MedRXiv: doi.org/10. 1101/2021.02.08.21251316. Received by Neurology February 12, 2021. Accepted in final form August 27, 2021.

Appendix Authors

\begin{tabular}{|c|c|c|}
\hline Name & Location & Contribution \\
\hline $\begin{array}{l}\text { Steve Simpson- } \\
\text { Yap, PhD, MPH }\end{array}$ & $\begin{array}{l}\text { CORe, Department of } \\
\text { Medicine, The University } \\
\text { of Melbourne, Australia; } \\
\text { Neuroepidemiology Unit, } \\
\text { Melbourne School of } \\
\text { Population \& Global } \\
\text { Health, The University of } \\
\text { Melbourne, Australia; } \\
\text { Menzies Institute for } \\
\text { Medical Research, } \\
\text { University of Tasmania, } \\
\text { Australia }\end{array}$ & $\begin{array}{l}\text { Drafting/revision of the } \\
\text { manuscript for content, } \\
\text { including medical writing } \\
\text { for content; major role in } \\
\text { the acquisition of data; } \\
\text { study concept or design; } \\
\text { analysis or interpretation } \\
\text { of data }\end{array}$ \\
\hline
\end{tabular}

\begin{tabular}{ll}
\hline Edward De & ESAT-STADIUS, KU \\
Brouwer, MSc & Leuven, Belgium
\end{tabular}

Drafting/revision of the manuscript for content, including medical writing for content; major role in the acquisition of data; study concept or design; analysis or interpretation of data

\begin{tabular}{lll}
\hline $\begin{array}{l}\text { Tomas Kalincik, } \\
\text { MD, PhD, } \\
\text { PGCertBiostat }\end{array}$ & $\begin{array}{l}\text { CORe, Department of } \\
\text { Medicine, The University } \\
\text { of Melbourne, Australia; } \\
\text { Melbourne MS Centre, } \\
\text { Department of Neurology, } \\
\text { Royal Melbourne } \\
\text { Hospital, Australia }\end{array}$ & $\begin{array}{l}\text { Drafting/revision } \\
\text { of the manuscript for } \\
\text { content, including } \\
\text { medical writing for } \\
\text { or design; analysis } \\
\text { or interpretation } \\
\text { of data }\end{array}$ \\
& & $\begin{array}{l}\text { Drafting/revision of the } \\
\text { manuscript for content, } \\
\text { Nick Rijke, MA }\end{array}$ \\
& MS International & $\begin{array}{l}\text { Federation, UK } \\
\text { for content; study concept } \\
\end{array}$ \\
& & or design
\end{tabular}


Appendix (continued)

\begin{tabular}{lll}
\hline Name & Location & Contribution \\
\hline $\begin{array}{l}\text { Jan A Hillert, MD, } \\
\text { PhD }\end{array}$ & $\begin{array}{l}\text { Department of Clinical } \\
\text { Neuroscience, Swedish } \\
\text { MS Registry, Sweden }\end{array}$ & $\begin{array}{l}\text { Drafting/revision of the } \\
\text { manuscript for content, } \\
\text { including medical writing } \\
\text { for content; major role in } \\
\text { the acquisition of data; } \\
\text { study concept or design; } \\
\text { analysis or interpretation } \\
\text { of data }\end{array}$ \\
\hline $\begin{array}{ll}\text { Clare Walton, } \\
\text { PhD }\end{array}$ & MS International & $\begin{array}{l}\text { Drafting/revision of the } \\
\text { manuscript for content, } \\
\text { including medical writing } \\
\text { for content; study concept } \\
\text { or design }\end{array}$ \\
\hline
\end{tabular}

Gilles Edan, MD Department of Neurology, Drafting/revision of the CHU Pontchaillou, France manuscript for content, including medical writing for content; study concept or design; analysis or interpretation of data

\begin{tabular}{|c|c|c|}
\hline $\begin{array}{l}\text { Yves Moreau, } \\
\text { PhD }\end{array}$ & $\begin{array}{l}\text { ESAT-STADIUS, KU } \\
\text { Leuven, Belgium }\end{array}$ & $\begin{array}{l}\text { Drafting/revision of the } \\
\text { manuscript for content, } \\
\text { including medical writing } \\
\text { for content; major role in } \\
\text { the acquisition of data; } \\
\text { study concept or design; } \\
\text { analysis or interpretation }\end{array}$ \\
\hline
\end{tabular}
of data

\begin{tabular}{lll}
\hline Tim Spelman, & $\begin{array}{l}\text { Department of Clinical } \\
\text { PhD }\end{array}$ & $\begin{array}{l}\text { Drafting/revision of the } \\
\text { manuscript for content, } \\
\text { MS Registry, Swedish; } \\
\text { Karolinska Institutet, } \\
\text { Sweden }\end{array}$ \\
$\begin{array}{ll}\text { including medical } \\
\text { writing for content; } \\
\text { study concept or design; } \\
\text { analysis or interpretation } \\
\text { of data }\end{array}$ \\
\end{tabular}

Lotte Geys, PhD Biomedical Research Drafting/revision of the Institute-Data Science manuscript for content, Institute, Hasselt including medical writing University, Belgium for content; study concept or design

\begin{tabular}{|c|c|c|}
\hline Tina Parciak, MSc & $\begin{array}{l}\text { Department of Medical } \\
\text { Informatics, University } \\
\text { Medical Center Göttingen, } \\
\text { Germany }\end{array}$ & $\begin{array}{l}\text { Drafting/revision of the } \\
\text { manuscript for content, } \\
\text { including medical writing } \\
\text { for content; study concept } \\
\text { or design }\end{array}$ \\
\hline $\begin{array}{l}\text { Clement } \\
\text { Gautrais, PhD }\end{array}$ & $\begin{array}{l}\text { Department of Computer } \\
\text { Science and Al, KU Leuven, } \\
\text { Belgium }\end{array}$ & $\begin{array}{l}\text { Drafting/revision of the } \\
\text { manuscript for content, } \\
\text { including medical writing } \\
\text { for content; study concept } \\
\text { or design }\end{array}$ \\
\hline $\begin{array}{l}\text { Nikola Lazovski, } \\
\text { PDEng }\end{array}$ & QMENTA, Spain & $\begin{array}{l}\text { Drafting/revision of the } \\
\text { manuscript for content, } \\
\text { including medical writing } \\
\text { for content; study concept } \\
\text { or design }\end{array}$ \\
\hline $\begin{array}{l}\text { Ashkan Pirmani, } \\
\text { MSc }\end{array}$ & $\begin{array}{l}\text { Medpace Reference } \\
\text { Laboratories, Molecular } \\
\text { Unit, Leuven, Belgium }\end{array}$ & $\begin{array}{l}\text { Drafting/revision of the } \\
\text { manuscript for content, } \\
\text { including medical writing } \\
\text { for content; study concept } \\
\text { or design }\end{array}$ \\
\hline $\begin{array}{l}\text { Amin } \\
\text { Ardeshirdavanai, } \\
\text { PhD }\end{array}$ & $\begin{array}{l}\text { Medpace Reference } \\
\text { Laboratories, Molecular } \\
\text { Unit, Leuven, Belgium }\end{array}$ & $\begin{array}{l}\text { Drafting/revision } \\
\text { of the manuscript for } \\
\text { content, including } \\
\text { medical writing for } \\
\text { content; study } \\
\text { concept or design }\end{array}$ \\
\hline
\end{tabular}

Appendix (continued)

\begin{tabular}{|c|c|c|}
\hline Name & Location & Contribution \\
\hline $\begin{array}{l}\text { Lars Forsberg, } \\
\text { MSc }\end{array}$ & $\begin{array}{l}\text { Department of Clinical } \\
\text { Neuroscience, Swedish } \\
\text { MS Registry, Sweden }\end{array}$ & $\begin{array}{l}\text { Drafting/revision of the } \\
\text { manuscript for content, } \\
\text { including medical writing } \\
\text { for content; study concept } \\
\text { or design }\end{array}$ \\
\hline
\end{tabular}

\begin{tabular}{ll}
\hline Anna Glaser, PhD & Department of Clinical \\
& Neuroscience, Swedish \\
& MS Registry, Sweden
\end{tabular}

Drafting/revision of the manuscript for content, including medical writing for content; major role in the acquisition of data; analysis or interpretation of data

\begin{tabular}{ll}
\hline $\begin{array}{l}\text { Robert } \\
\text { McBurney, PhD }\end{array}$ & $\begin{array}{l}\text { iConquerMS People- } \\
\text { Powered Research } \\
\text { Network, Accelerated } \\
\text { Cure Project for MS, } \\
\text { Waltham, MA }\end{array}$ \\
\hline $\begin{array}{l}\text { Hollie Schmidt, } \\
\text { MS }\end{array}$ & $\begin{array}{l}\text { iConquerMS People- } \\
\text { Powered Research } \\
\text { Network, Accelerated } \\
\text { Cure Project for MS, }\end{array}$ \\
$\begin{array}{l}\text { Waltham, MA } \\
\begin{array}{l}\text { Arnfin B. } \\
\text { Bergmann, MD, } \\
\text { PhD }\end{array}\end{array}$ & $\begin{array}{l}\text { NeuroTransData Study } \\
\text { Group, NeuroTransData, }\end{array}$ \\
\hline
\end{tabular}

Drafting/revision of the manuscript for content including medical writing for content; major role in the acquisition of data

Drafting/revision of the manuscript for content, including medical writing for content; major role in the acquisition of data

Drafting/revision of the manuscript for content, including medical writing for content; major role in the acquisition of data

\begin{tabular}{lll}
\hline Stefan Braune, & $\begin{array}{l}\text { NeuroTransData Study } \\
\text { GhD }\end{array}$ & $\begin{array}{l}\text { Drafting/revision of the } \\
\text { Germany }\end{array}$ \\
& & $\begin{array}{l}\text { manuscript for content, } \\
\text { including medical writing } \\
\text { for content; major role in } \\
\text { the acquisition of data }\end{array}$
\end{tabular}

\begin{tabular}{|c|c|c|}
\hline $\begin{array}{l}\text { Alexander } \\
\text { Stahmann, MSc }\end{array}$ & $\begin{array}{l}\text { German MS-Register by } \\
\text { the National MS Society, } \\
\text { MS Forschungs- und } \\
\text { Projektentwicklungs- } \\
\text { gGmbH, Germany }\end{array}$ & $\begin{array}{l}\text { Drafting/revision of the } \\
\text { manuscript for content, } \\
\text { including medical writing } \\
\text { for content; major role in } \\
\text { the acquisition of data }\end{array}$ \\
\hline $\begin{array}{l}\text { Rodden } \\
\text { Middleton, MBA }\end{array}$ & $\begin{array}{l}\text { UK MS Register, Swansea } \\
\text { University, UK }\end{array}$ & $\begin{array}{l}\text { Drafting/revision of the } \\
\text { manuscript for content, } \\
\text { including medical writing } \\
\text { for content; major role in } \\
\text { the acquisition of data }\end{array}$ \\
\hline $\begin{array}{l}\text { Amber Salter, } \\
\text { PhD }\end{array}$ & $\begin{array}{l}\text { COViMS, US; Division of } \\
\text { Biostatistics, Washington } \\
\text { University in St. Louis, MO }\end{array}$ & $\begin{array}{l}\text { Drafting/revision of the } \\
\text { manuscript for content, } \\
\text { including medical writing } \\
\text { for content; major role in } \\
\text { the acquisition of data }\end{array}$ \\
\hline Robert J. Fox, MD & $\begin{array}{l}\text { COViMS, US; Mellen } \\
\text { Center for Multiple } \\
\text { Sclerosis, Cleveland Clinic, } \\
\text { OH }\end{array}$ & $\begin{array}{l}\text { Drafting/revision of the } \\
\text { manuscript for content, } \\
\text { including medical writing } \\
\text { for content; major role in } \\
\text { the acquisition of data }\end{array}$ \\
\hline $\begin{array}{l}\text { Anneke van der } \\
\text { Walt, PhD }\end{array}$ & $\begin{array}{l}\text { Department of } \\
\text { Neuroscience, Central } \\
\text { Clinical School, Monash } \\
\text { University, Australia }\end{array}$ & $\begin{array}{l}\text { Drafting/revision of the } \\
\text { manuscript for content, } \\
\text { including medical writing } \\
\text { for content; major role in } \\
\text { the acquisition of data }\end{array}$ \\
\hline $\begin{array}{l}\text { Helmut } \\
\text { Butzkueven, PhD }\end{array}$ & $\begin{array}{l}\text { Department of } \\
\text { Neuroscience, Central } \\
\text { Clinical School, Monash } \\
\text { University, Australia }\end{array}$ & $\begin{array}{l}\text { Drafting/revision of } \\
\text { the manuscript for } \\
\text { content, including } \\
\text { medical writing for } \\
\text { content; major role } \\
\text { in the acquisition } \\
\text { of data }\end{array}$ \\
\hline
\end{tabular}


Appendix (continued)

\begin{tabular}{|c|c|c|}
\hline Name & Location & Contribution \\
\hline $\begin{array}{l}\text { Raed Alroughani, } \\
\text { PhD }\end{array}$ & Al-Amiri Hospital, Kuwait & $\begin{array}{l}\text { Drafting/revision of the } \\
\text { manuscript for content, } \\
\text { including medical writing } \\
\text { for content; major role in } \\
\text { the acquisition of data }\end{array}$ \\
\hline $\begin{array}{l}\text { Serkan Ozakbas, } \\
\text { PhD }\end{array}$ & $\begin{array}{l}\text { Dokuz Eylul University, } \\
\text { Turkey }\end{array}$ & $\begin{array}{l}\text { Drafting/revision of the } \\
\text { manuscript for content, } \\
\text { including medical writing } \\
\text { for content; major role in } \\
\text { the acquisition of data }\end{array}$ \\
\hline Juan I. Rojas, MSc & $\begin{array}{l}\text { Neurology Department, } \\
\text { Hospital Universitario de } \\
\text { CEMIC, Argentina; } \\
\text { RELACOEM, Argentina }\end{array}$ & $\begin{array}{l}\text { Drafting/revision of the } \\
\text { manuscript for content, } \\
\text { including medical writing } \\
\text { for content; major role in } \\
\text { the acquisition of data }\end{array}$ \\
\hline $\begin{array}{l}\text { Ingrid van der } \\
\text { Mei, PhD }\end{array}$ & $\begin{array}{l}\text { Australian MS } \\
\text { Longitudinal Study, } \\
\text { Menzies Institute for } \\
\text { Medical Research, } \\
\text { University of Tasmania, } \\
\text { Australia }\end{array}$ & $\begin{array}{l}\text { Drafting/revision of the } \\
\text { manuscript for content, } \\
\text { including medical writing } \\
\text { for content; major role in } \\
\text { the acquisition of data; } \\
\text { analysis or interpretation } \\
\text { of data }\end{array}$ \\
\hline
\end{tabular}

Nupur Nag, PhD Neuroepidemiology Unit, Drafting/revision of the Melbourne School of manuscript for content, Population \& Global including medical writing Health, The University of for content; major role in Melbourne, Australia the acquisition of data

\begin{tabular}{lll}
\hline Rumen Ivanov, & Bulgarian SmartMS & Drafting/revision of the \\
MSc & COVID-19 Dataset, & manuscript for content, \\
Bulgaria & including medical writing \\
& for content; major role in \\
& the acquisition of data
\end{tabular}

\begin{tabular}{lll}
\hline $\begin{array}{l}\text { Guilherme } \\
\text { Sciascia do Olival, } \\
\text { PhD }\end{array}$ & $\begin{array}{l}\text { ABEM-Brazilian MS } \\
\text { Patients Association, } \\
\text { Brazil }\end{array}$ & $\begin{array}{l}\text { Drafting/revision of the } \\
\text { manuscript for content, } \\
\text { including medical writing } \\
\text { for content; major role in } \\
\text { the acquisition of data }\end{array}$ \\
\hline $\begin{array}{l}\text { Alice Estavo Dias, } \\
\text { PhD }\end{array}$ & $\begin{array}{l}\text { ABEM-Brazilian MS } \\
\text { Patients Association, } \\
\text { Brazil }\end{array}$ & $\begin{array}{l}\text { Drafting/revision of the } \\
\text { manuscript for content, } \\
\text { including medical writing } \\
\text { for content; major role in } \\
\text { the acquisition of data }\end{array}$
\end{tabular}

Melinda Magyari, Danish Multiple Sclerosis Drafting/revision of the PhD Registry, Department of manuscript for content, Neurology, University including medical writing Hospital Rigshospitalet, for content; major role in Denmark the acquisition of data

\begin{tabular}{lll}
\hline $\begin{array}{l}\text { Doralina Brum, } \\
\text { PhD }\end{array}$ & $\begin{array}{l}\text { Universidade Estadual } \\
\text { Paulista, Unesp, } \\
\text { Faculdade de Medicina, } \\
\text { Botucatu, Brazil; } \\
\text { REDONE.br-Brazilian } \\
\text { Registry of Multiple } \\
\text { Sclerosis and }\end{array}$ & $\begin{array}{l}\text { Drafting/revision of the } \\
\text { manuscript for content, } \\
\text { including medical writing } \\
\text { for content; major role in } \\
\text { the acquisition of data }\end{array}$ \\
& $\begin{array}{l}\text { Neuromyelitis Optica } \\
\text { Spectrum Disorders, }\end{array}$ & \\
& Brazil & \\
\hline Maria Fernanda & REDONE.br-Brazilian & Drafting/revision of the \\
Mendes, PhD & Registry of Multiple & manuscript for content, \\
& Sclerosis and & including medical writing \\
& Neuromyelitis Optica & for content; major role in \\
& Spectrum Disorders, & the acquisition of data \\
& Brazil; Irmandade da & \\
& Santa Casa de & \\
& Misericórdia de São Paulo, \\
& Brazil
\end{tabular}

Appendix (continued)

\begin{tabular}{|c|c|c|}
\hline Name & Location & Contribution \\
\hline $\begin{array}{l}\text { Ricardo N. } \\
\text { Alonso, MD, MSc }\end{array}$ & $\begin{array}{l}\text { RELACOEM, Argentina; } \\
\text { Multiple Sclerosis } \\
\text { University Center, Ramos } \\
\text { Mejia Hospital-EMA, } \\
\text { Argentina }\end{array}$ & $\begin{array}{l}\text { Drafting/revision of the } \\
\text { manuscript for content, } \\
\text { including medical writing } \\
\text { for content; major role in } \\
\text { the acquisition of data }\end{array}$ \\
\hline $\begin{array}{l}\text { Richard S. } \\
\text { Nicholas, PhD }\end{array}$ & $\begin{array}{l}\text { UK MS Register, Swansea } \\
\text { University, UK; Imperial } \\
\text { College London, UK; } \\
\text { Swansea University, UK }\end{array}$ & $\begin{array}{l}\text { Drafting/revision of the } \\
\text { manuscript for content, } \\
\text { including medical writing } \\
\text { for content; major role in } \\
\text { the acquisition of data }\end{array}$ \\
\hline $\begin{array}{l}\text { Johana Bauer, } \\
\text { PhD }\end{array}$ & $\begin{array}{l}\text { Mental Health Area, EMA, } \\
\text { Argentina }\end{array}$ & $\begin{array}{l}\text { Drafting/revision of the } \\
\text { manuscript for content, } \\
\text { including medical writing } \\
\text { for content; major role in } \\
\text { the acquisition of data }\end{array}$ \\
\hline $\begin{array}{l}\text { Aníbal Sebastián } \\
\text { Chertcoff, MD }\end{array}$ & $\begin{array}{l}\text { MS and Demyelinating } \\
\text { Diseases. Hospital } \\
\text { Británico de Buenos Aires, } \\
\text { EMA, Argentina }\end{array}$ & $\begin{array}{l}\text { Drafting/revision of the } \\
\text { manuscript for content, } \\
\text { including medical writing } \\
\text { for content; major role in } \\
\text { the acquisition of data }\end{array}$ \\
\hline Anna Zabalza, MD & $\begin{array}{l}\text { Servei de Neurologia- } \\
\text { Neuroimmunologia, } \\
\text { Centre d'Esclerosi } \\
\text { Múltiple de Catalunya, } \\
\text { (Cemcat); Vall d'Hebron } \\
\text { Institut de Recerca, Vall } \\
\text { d'Hebron Hospital } \\
\text { Universitari; Universitat } \\
\text { Autònoma de Barcelona, } \\
\text { Spain }\end{array}$ & $\begin{array}{l}\text { Drafting/revision of the } \\
\text { manuscript for content, } \\
\text { including medical writing } \\
\text { for content; major role in } \\
\text { the acquisition of data }\end{array}$ \\
\hline
\end{tabular}

\begin{tabular}{|c|c|c|}
\hline $\begin{array}{l}\text { Georgina } \\
\text { Arrambide, MD, } \\
\text { PhD }\end{array}$ & $\begin{array}{l}\text { Servei de Neurologia- } \\
\text { Neuroimmunologia, } \\
\text { Centre d'Esclerosi } \\
\text { Múltiple de Catalunya, } \\
\text { (Cemcat); Vall d'Hebron } \\
\text { Institut de Recerca, Vall } \\
\text { d'Hebron Hospital } \\
\text { Universitari; Universitat } \\
\text { Autònoma de Barcelona, } \\
\text { Spain }\end{array}$ & $\begin{array}{l}\text { Drafting/revision of the } \\
\text { manuscript for content, } \\
\text { including medical writing } \\
\text { for content; major role in } \\
\text { the acquisition of data }\end{array}$ \\
\hline $\begin{array}{l}\text { Alexander Fidao, } \\
\text { MPH }\end{array}$ & $\begin{array}{l}\text { Neuroepidemiology Unit, } \\
\text { Melbourne School of } \\
\text { Population \& Global } \\
\text { Health, The University of } \\
\text { Melbourne, Australia }\end{array}$ & $\begin{array}{l}\text { Drafting/revision of the } \\
\text { manuscript for content, } \\
\text { including medical writing } \\
\text { for content; analysis or } \\
\text { interpretation of data }\end{array}$ \\
\hline $\begin{array}{l}\text { Giancarlo Comi, } \\
\text { MD }\end{array}$ & $\begin{array}{l}\text { Institute of Experimental } \\
\text { Neurology, Ospedale San } \\
\text { Raffaele, Italy }\end{array}$ & $\begin{array}{l}\text { Drafting/revision of the } \\
\text { manuscript for content, } \\
\text { including medical writing } \\
\text { for content; major role in } \\
\text { the acquisition of data; } \\
\text { study concept or design }\end{array}$ \\
\hline $\begin{array}{l}\text { Liesbet Peeters, } \\
\text { PhD }\end{array}$ & $\begin{array}{l}\text { Biomedical Research } \\
\text { Institute-Data Science } \\
\text { Institute, Hasselt } \\
\text { University, Belgium }\end{array}$ & $\begin{array}{l}\text { Drafting/revision of the } \\
\text { manuscript for content, } \\
\text { including medical writing } \\
\text { for content; study concept } \\
\text { or design }\end{array}$ \\
\hline
\end{tabular}

\section{References}

1. Luna G, Alping P, Burman J, et al. Infection risks among patients with multiple sclerosis treated with fingolimod, natalizumab, rituximab, and injectable therapies. JAMA Neurol. 2019;77(2):184-191.

2. Salter A, Fox RJ, Newsome SD, et al. Outcomes and risk factors associated with SARSCoV-2 infection in a North American registry of patients with multiple sclerosis. JAMA Neurol. 2021;78(6):699-708.

3. Louapre C, Collongues N, Stankoff B, et al. Clinical characteristics and outcomes in patients with coronavirus disease 2019 and multiple sclerosis. JAMA Neurol. 2020; 77(9):1079-1088. 
4. Evangelou N, Garjani A, dasNair R, et al. Self-diagnosed COVID-19 in people with multiple sclerosis: a community-based cohort of the UK MS Register. J Neurol Neurosurg Psychiatry. 2020;92(1):107-109.

5. Sormani MP, De Rossi N, Schiavetti I, et al. Disease modifying therapies and covid-19 severity in multiple sclerosis. Ann Neurol. 2021;89(4):780-789.

6. Peeters LM, Parciak T, Walton C, et al. COVID-19 in people with multiple sclerosis: a global data sharing initiative. Mult Scler. 2020;26(10):1157-1162.

7. Kurtzke JF. Rating neurologic impairment in multiple sclerosis: an Expanded Disability Status Scale (EDSS). Neurology. 1983;33(11):1444-1452.

8. D'Souza M, Yaldizli Ö, John R, et al. Neurostatus e-scoring improves consistency of Expanded Disability Status Scale assessments: a proof of concept study. Mult Scler. 2017;23(4):597-603.

9. Mehta D, Miller C, Arnold DL, et al. Effect of dimethyl fumarate on lymphocytes in RRMS: implications for clinical practice. Neurology. 2019;92(15):e1724-e1738.

10. Baker D, Amor S, Kang AS, Schmierer K, Giovannoni G. The underpinning biology relating to multiple sclerosis disease modifying treatments during the COVID-19 pandemic. Mult Scler Relat Disord. 2020;43:102174.
11. Wijnands JMA, Zhu F, Kingwell E, et al. Disease-modifying drugs for multiple sclerosis and infection risk: a cohort study. J Neurol Neurosurg Psychiatry. 2018;89(10):1050-1056.

12. Myhr KM, Torkildsen Ø, Lossius A, Bø L, Holmøy T. B cell depletion in the treatment of multiple sclerosis. Expert Opin Biol Ther. 2019;19(3):261-271.

13. Klein C, Lammens A, Schäfer W, et al. Epitope interactions of monoclonal antibodies targeting CD20 and their relationship to functional properties. $m A$ ss. 2013;5(1):22-33.

14. Gelfand JM, Cree BAC, Hauser SL. Ocrelizumab and other CD20(+) B-cell-depleting therapies in multiple sclerosis. Neurotherapeutics. 2017;14(4):835-841.

15. Atlas of MS, 3rd ed. Multiple Sclerosis International Federation;2020.

16. Marrie RA, Cutter G, Tyry T, Campagnolo D, Vollmer T. Smoking status over two years in patients with multiple sclerosis. Neuroepidemiology. 2009;32(1):72-79.

17. Ponsonby AL, Lucas RM, Dear K, et al. The physical anthropometry, lifestyle habits and blood pressure of people presenting with a first clinical demyelinating even compared to controls: the Ausimmune study. Mult Scler. 2013;19(13):1717-1725.

18. Pittas F, Ponsonby AL, van der Mei IA, et al. Smoking is associated with progressive disease course and increased progression in clinical disability in a prospective cohort of people with multiple sclerosis. J Neurol. 2009;256(4):577-585. 


\section{Neurology}

\section{Associations of Disease-Modifying Therapies With COVID-19 Severity in Multiple Sclerosis}

Steve Simpson-Yap, Edward De Brouwer, Tomas Kalincik, et al.

Neurology 2021;97;e1870-e1885 Published Online before print October 5, 2021

DOI 10.1212/WNL.0000000000012753

This information is current as of October 5, 2021

\section{Updated Information \&} Services

References

Citations

Subspecialty Collections

Permissions \& Licensing

Reprints including high resolution figures, can be found at: http://n.neurology.org/content/97/19/e1870.full

This article cites 17 articles, 3 of which you can access for free at: http://n.neurology.org/content/97/19/e1870.full\#ref-list-1

This article has been cited by 2 HighWire-hosted articles: http://n.neurology.org/content/97/19/e1870.full\#\#otherarticles

This article, along with others on similar topics, appears in the following collection(s):

\section{Cohort studies}

http://n.neurology.org/cgi/collection/cohort_studies COVID-19

http://n.neurology.org/cgi/collection/covid_19

Multiple sclerosis

http://n.neurology.org/cgi/collection/multiple_sclerosis

Information about reproducing this article in parts (figures,tables) or in its entirety can be found online at:

http://www.neurology.org/about/about_the_journal\#permissions

Information about ordering reprints can be found online:

http://n.neurology.org/subscribers/advertise

Neurology ${ }^{\circledR}$ is the official journal of the American Academy of Neurology. Published continuously since 1951, it is now a weekly with 48 issues per year. Copyright Copyright ( 2021 The Author(s). Published by Wolters Kluwer Health, Inc. on behalf of the American Academy of Neurology.. All rights reserved. Print ISSN: 0028-3878. Online ISSN: 1526-632X.

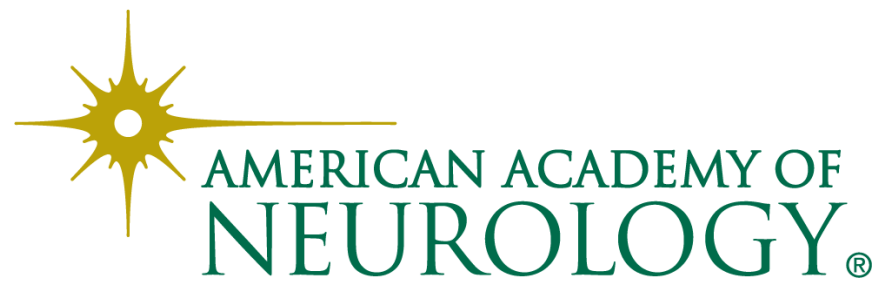

